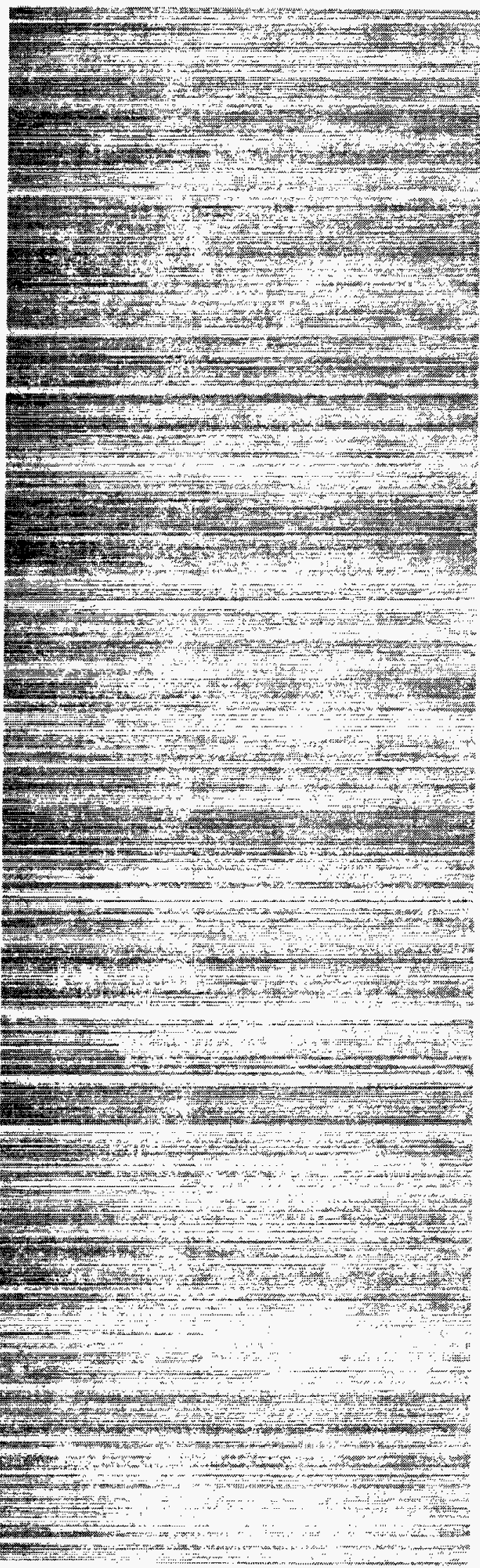

\section{Tokamak Physics Experiment:}

\section{Diagnostic Windows Study}

\section{RECEIVED \\ NOV 201995 \\ OSTI}

\section{Los Alamos}

NATIONAL LABORATORY

Los Alamos National Laboratory is operated by the University of California for the United States Department of Energy under contract W-7405-ENG-36. 
Photocomposition by E. Katherine Valdez, Group CIC-1

This work was supported by the U.S. Department of Energy and the Princeton Plasma Physics Laboratory Tokamak Physics Experiment.

An Affirmative Action/Equal Opportunity Employer

This report was prepared as an account of work sponsored by an agency of the United States Government. Neither The Regents of the University of California, the United States

Government nor any agency thereof, nor any of their employees, makes any warranty, express or implied, or assumes any legal liability or responsibility for the accuracy, completeness, or usefulness of any information, apparatus, product, or process disclosed, or represents that its use would not infringe privately owned rights. Reference herein to any specific commercial product, process, or service by trade name, trademark, manufacturer, or otherwise, does not necessarily constitute or imply its endorsement, recommendation, or favoring by The Regents of the University of California, the United States Government, or any agency thereof. The views and opinions of authors expressed herein do not necessarily state or reflect those of The Regents of the University of California, the United States Government, or any agency thereof. 
$U C-426$

Issued: November 1995

Tokamak Physics Experiment:

Diagnostic Windows Study

M. Merrigan

G. A. Wurden 


\section{DISCLAIMER}

Portions of this document may be illegible in electronic image products. Images are produced from the best available original document. 


\section{CONTENTS}

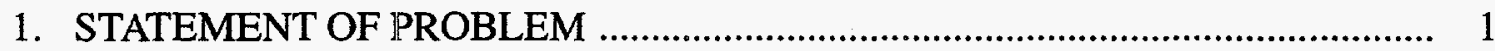

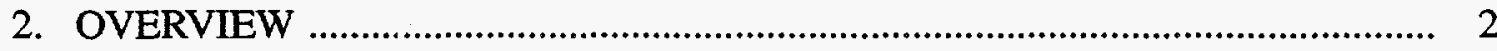

2.1. TPX Description .......................................................................................... 2

2.2. Summary of Planned TPX Diagnostics with Window Requirements ............ 2

3. REVIEW OF TOKAMAK PLASMA RADIATION CHARACTERISTICS ......... 5

4. WINDOW MATERIAL PROPERTIES _........................................................... 6

5. CALCULATED WINDOW TEMPERATURES AND STRESSES FOR TPX WINDOWS COOL.ED BY STRUCTURAL HEAT SINKING ONLY .................. 6

5.1. Window Temperatures ................................................................................... 6

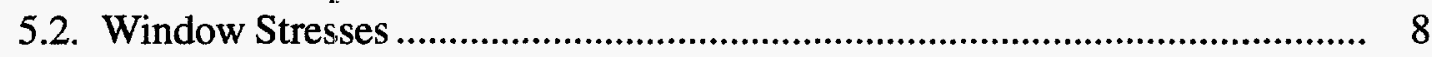

6. REVIEW OF RELATED WINDOW-COOLING TECHNOLOGY ....................... 11

6.1. Laser Window-Cooling Technology ........................................................ 11

6.2. Endoatmospheric Missile Window-Cooling Technology ............................... 12

7. DEVELOPMENT OF TPX DIAGNOSTIC WINDOW-COOLING CONCEPT ... 13

7.1. Attenuation of Window Radiation Loads by Re-entrant Mirrors ................... 14

7.2. Use of High-Thermal-Conductivity Window Coating ...................................... 14

7.3. Increased Window Conductance by Micro-Heat Pipe …................................ 14

7.4. Window Surface Cooling (Gas) by Forced Convection .................................. 20

7.5. Window Cooling by Internal Forced Convection (Microchannel) .................. 20

7.6. Periodic Shielding of the Window Aperture ................................................ 29

7.7. Use of Transparent Radiation Shields .......................................................... 30

8. CONCLUSIONS AND RECOMMENDATIONS ……...................................... 30

9. RECOMMENDED WINDOW DEVELOPMENT PROGRAM .......................... 32

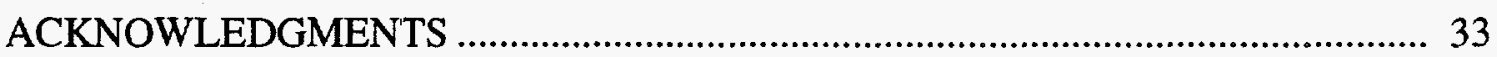

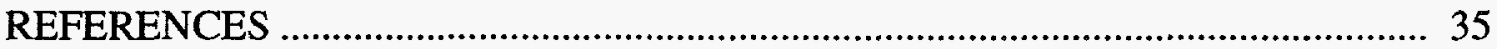

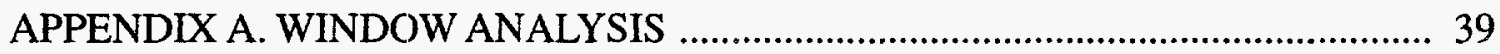

APPENDIX B. WINDOW SCENARIOS ………................................................ 41 


\section{FIGURES}

Fig. 2.1. Schematic elevation view of the TPX.................................................... 3

Fig. 5.1. $\Delta \mathrm{T}$ in TPX windows for various materials and incident flux levels. ........... 8

Fig. 5.2. Thermal stress in TPX windows for various materials and incident flux levels....................................................................................... 10

Fig. 7.1. Axial/surface area ratio versus the window blockage factor. ....................... 16

Fig. 7.2. q" surface versus the window blockage factor with heat pipe length-to-height ratios as a parameter.

Fig. 7.3. $\quad \mathrm{A}_{\text {surface }} / \mathrm{A}_{\text {radial }}$ versus the window blockage factor. ...................................... 18

Fig. 7.4. $\mathrm{q}_{\text {surface }}$ versus the window blockage factor with heat pipe length-to-height ratios as a parameter.

Fig. 7.5. Window cooled by a micro-heat pipe.

Fig. 7.6. Schematic configuration of a semiconductor heat sink employing microchannel cooling. Typical fin and channel widths are $50 \mu \mathrm{m}$.

Fig. 7.7. Aperture blockage versus surface heat flux for a typical microchannel-cooled IR window.

Fig. 7.8. Effect of the number of microchannels on the percentage of window blockage. 24

Fig. 7.9. Nomenclature for microchannel analysis. 25

Fig. 7.10. Effect of microchannel depth on temperature difference. 26

Fig. 7.11. Effect of microchannel aspect ratio on percent aperture blockage. 27

Fig. 7.12. Effect of window conductivity on the temperature difference between the microchannel surface and the window surface. 28

Fig. 7.13. Schematic of an internally cooled window using microchannels................. 28

Fig. 9.1. Possible Gantt chart of proposed windows research and development. ....... 34

\section{TABLES}

Table 2.1. Planned TPX Diagnostics

Table 4.1. Window Material Properties

Table 5.1. $\Delta \mathrm{T}$ (Edge to Centerline) at $40 \mathrm{~W} / \mathrm{cm}^{2}\left({ }^{\circ} \mathrm{C}\right)$

Table 5.2. Peak Thermal Stress (psi) in Edge-Cooled Windows for the Case of $40 \mathrm{~W} / \mathrm{cm}^{2}$ Heat Flux

Table 6.1. Absorbed-Flux-Density Limits: 1-s CW Laser Run Time............................ 12

Table 7.1. Capabilities and Limitations of Micro-Heat Pipes ......................................... 15

Table 7.2. Demonstrated Capability of Microchannel Cooling ...................................... 21

Table 7.3. Baseline Characteristics for Microchannel-Cooled Windows ....................... 29

Table 8.1. Comparison of Potential TPX Window-Cooling Methods ........................... 31 


\title{
TOKAMAK PHYSICS EXPERIMENT: DIAGNOSTIC WINDOWS STUDY
}

\author{
by
}

\author{
M. Merrigan and G. A. Wurden
}

\begin{abstract}
We detail the study of diagnostic windows and window thermal stress remediation in the long-pulse, high-power Tokamak Physics Experiment (TPX) operation. The operating environment of the TPX diagnostic windows is reviewed, thermal loads on the windows estimated, and cooling requirements for the windows considered. Applicable windowcooling technology from other fields is reviewed and its application to the TPX windows considered. Methods for TPX window thermal conditioning are recommended, with some discussion of potential implementation problems provided. Recommendations for further research and development work to ensure performance of windows in the TPX system are presented.
\end{abstract}

\section{STATEMENT OF PROBLEM}

Preliminary studies of the heat loads on the Tokamak Physics Experiment (TPX) diagnostic windows located at the port covers indicate that the windows, which range in size to about $10 \mathrm{~cm}$ in cliameter, may not survive the intense incident-radiated power for a full-length ( $>1000 \mathrm{~s}$ ) power pulse. The absorption of a large fraction of the radiated power in the window materials, coupled with the low thermal conductivity of the windows, may lead to unacceptable temperature and thermal stress increase in the window materials. Windows are an essential element in the performance of many key diagnostics, so a solution to the problem of getting optical signals with good spatial and spectral characteristics out of the tokamak is necessary. Window materials considered in this study include fused silica, crystal quartz, magnesium fluoride, and zinc selenide.

This study evolved from the initial modeling study by R. A. Ellis III (Ref. 1), reproduced in Appendix A, and also involved review of other applications of high thermal load windows such as those for high-power continuous-wave (CW) lasers, endoatmospheric missiles, and microwave gyrotrons. Tasks involved in the study included the following: 
- Review of the results and impact of the Ellis study. Evaluation of the results based on physical and optical properties of the window materials and the establishing of the limits of the problem quantitatively.

- Review of the data in window studies and development in nonmagnetic fusion fields to quantify experience relative to the TPX requirements.

- Review of data on the impact of radiation absorbed in the surface layer of windows in inducing short-range stresses. Consideration of the effects of the neutron bombardment on the susceptibility of the windows to mechanical stress (not performedthe windows will have to be changed if they blacken, anyway).

- Consideration of remediation techniques and their effectiveness, for example, material changes, active cooling, size limits, use of shields and mirrors in front of the windows. Proposal of potential solutions.

- Development of a recommended plan for a research and development program to ensure the performance of windows on the TPX.

\section{OVERVIEW}

\subsection{TPX Description}

The TPX is intended to provide a design basis for a continuously operated tokamak fusion reactor. It will have a long-pulse (1000-s) capability with consequent first-wall thermal loads approaching steady state. The long-pulse operation will produce $6 \times 10^{21}$ neutrons/yr, requiring remote maintenance of in-vessel hardware. The vacuum vessel and internal components will be cooled to $150^{\circ} \mathrm{C}$ during operation and heated to $350^{\circ} \mathrm{C}$ during bakeout. The vacuum vessel wall will be water-cooled to maintain wall temperature with flow rates set to a $20^{\circ} \mathrm{C}$ coolant temperature rise. Supply pressures for the coolant will be $530 \mathrm{kPa}$. The coolant will be demineralized, and deionized water will be routed to the vessel internal components and then to the space between the walls of the vacuum vessel, where it will also serve as a neutron shield. Bakeout heating will be accomplished by superheated steam at $530 \mathrm{kPa}$ and $350^{\circ} \mathrm{C}$. An elevation view of the TPX is shown in Fig. 2.1. The major radius of the toroidal vacuum vessel is $2.21 \mathrm{~m}$. Input power ranges from $18 \mathrm{MW}$ (baseline) to $45 \mathrm{MW}$ (maximum).

\subsection{Summary of Planned TPX Diagnostics with Window Requirements}

Currently, planned diagnostics for the TPX system are summarized in Table 2.1 (Refs. 1). Those diagnostic elements requiring windows are indicated in the table, together with an indication of the probable window material and a subjective estimate of the required window dimensions. The diameter range considered in the table is from about $1 \mathrm{~cm}$ (small) to $20 \mathrm{~cm}$ (largest). Window thickness will depend on the materials used but will range from approximately one-half the diameter for the smallest windows to about one-tenth the diameter for the largest windows. 


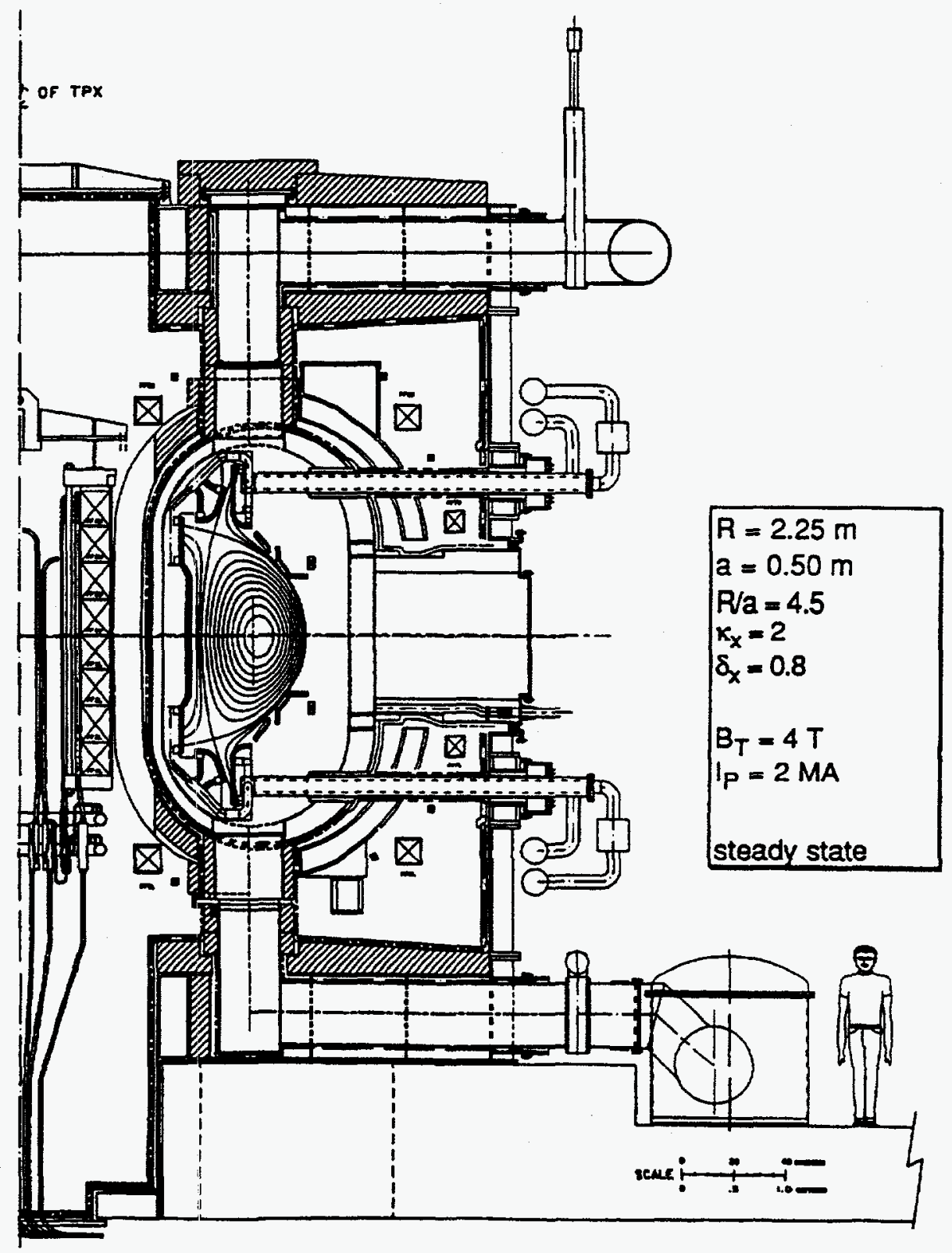

Fig. 2.1. Schematic elevation view of the TPX. 
Table 2.1. Planned TPX Diagnostics

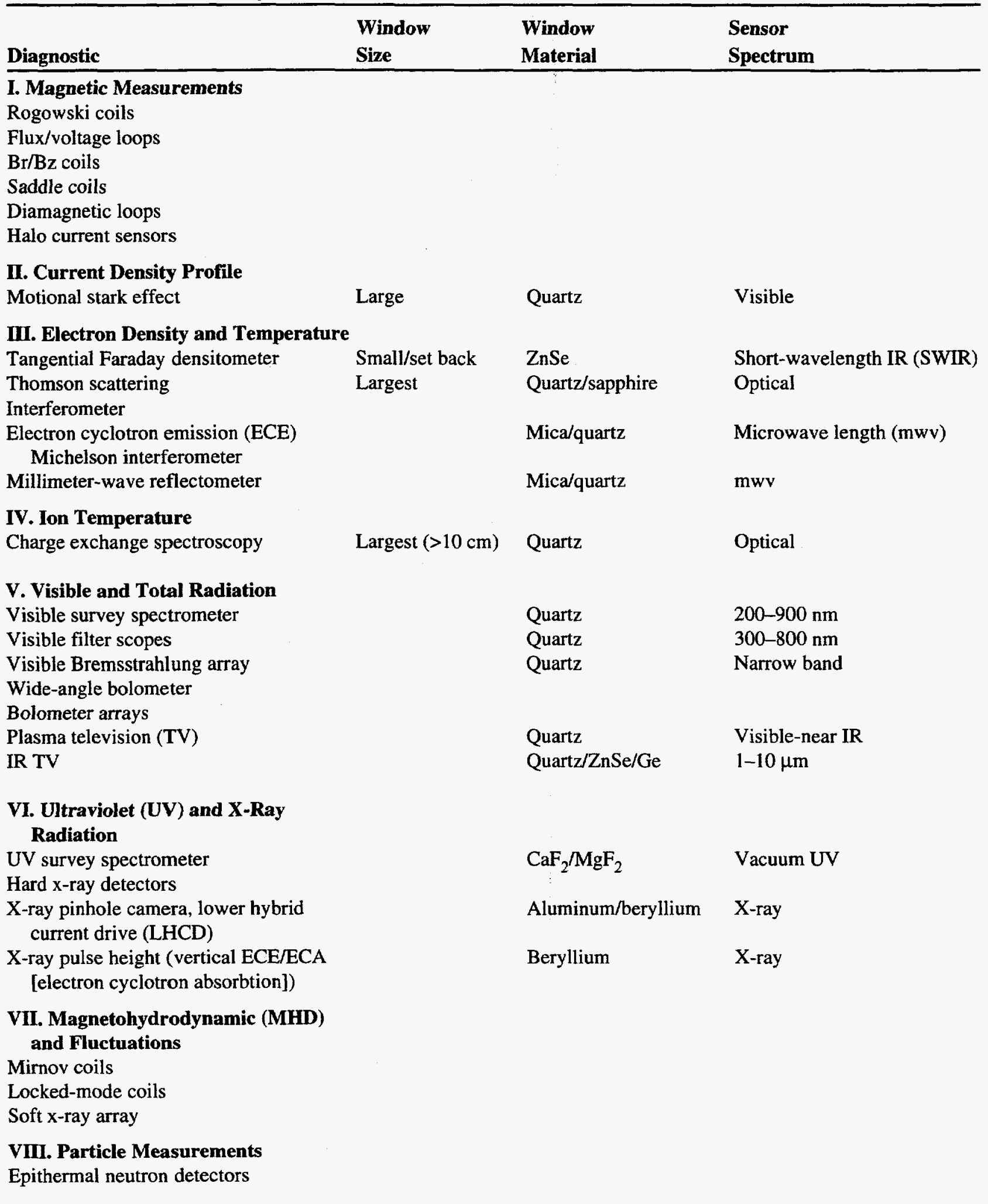


Table 2.1. Planned TPX Diagnostics (Cont.)

\begin{tabular}{|c|c|c|c|}
\hline Diagnostic & $\begin{array}{l}\text { Window } \\
\text { Size }\end{array}$ & $\begin{array}{l}\text { Window } \\
\text { Material }\end{array}$ & $\begin{array}{l}\text { Sensor } \\
\text { Spectrum }\end{array}$ \\
\hline \multicolumn{4}{|l|}{ IX. Divertor Diagnostics } \\
\hline Divertor IR TV & & $\begin{array}{l}\text { Quartz/ZnSe } \\
\mathrm{ZnSe} / \mathrm{Ge}\end{array}$ & $\begin{array}{l}\text { Optical } \\
0.8-2.0 \mu \mathrm{m} \\
1.0-10.0 \mu \mathrm{m}\end{array}$ \\
\hline \multirow{2}{*}{\multicolumn{4}{|c|}{$\begin{array}{l}\text { Foil bolometers } \\
\text { Divertor bolometer arrays }\end{array}$}} \\
\hline & & & \\
\hline Multichord visible spectrometer & & Quartz & $300-800 \mathrm{~nm}$ \\
\hline $\begin{array}{l}\text { Divertor } \mathrm{H}_{\alpha} \text { monitors } \\
\text { Erosion diagnostic } \\
\text { Neutral pressure gage }\end{array}$ & & Quartz & $650 \mathrm{~nm}$ \\
\hline \\
\hline \multirow{2}{*}{\multicolumn{4}{|c|}{$\begin{array}{l}\text { Thermocouples } \\
\text { Fixed-edge probes }\end{array}$}} \\
\hline & & & \\
\hline \multicolumn{4}{|l|}{ Torus ion gages } \\
\hline \multicolumn{4}{|l|}{ Residual gas analyzer (RGA) } \\
\hline \multicolumn{4}{|l|}{ Penning gage $(\mathrm{He})$} \\
\hline \multicolumn{4}{|l|}{$\begin{array}{l}\text { Glow discharge probe } \\
\text { Inspection illumination svstem }\end{array}$} \\
\hline Inspection illumination system & & & \\
\hline
\end{tabular}

\section{REVIEW OF TOKAMAK PLASMA RADIATION CHARACTERISTICS}

Impurities in tokamaks provide the dominant source (Ref. 2) of plasma radiation from the plasma boundary. The radiation incident on the diagnostic windows of the TPX will consist primarily of emission from oxygen, carbon, and nickel (typical heavy metal) contaminants. Anticipated levels of these contaminants are $3 \%$ carbon, $0.5 \%$ oxygen, and $0.01 \%$ nickel. For central plasma temperatures of $10 \mathrm{keV}$ and edges much cooler $(100-500 \mathrm{eV})$, the bulk of the plasma radiation will be from an annular shell, where contributions from these species is expected to be $\sim 100 \times$ Bremsstrahlung. The radiation spectrum will be peaked well above the visible range with negligible amounts of energy at wavelengths $>0.1 \mu \mathrm{ml}$ (Refs. 3, 4). An estimated distribution of percent energy versus wavelength is $80 \%$ at $40-60 \AA$ from carbon, $10 \%$ at $15-20 \AA$ from oxygen, and $10 \%$ in the range of $1000 \AA$ from hydrogen. This is not to say that continuum between $20-2000$ $\AA$ will not also be present-just that it is small compared with the line and associated free-bound recombination. For the purposes of this study, the precise details are unimportant, so long as the vast bulk of the radiation is at wavelengths shorter than the transmission bands of the materials, assuming that the power flux is not sufficiently high to instantly ablate the inner window surface. A more detailed wavelength distribution of the incident flux could be calculated from the estimated contaminant levels and temperature by using the MIST code for TPX parameters. Since present-day (Tokamak Fusion Test Reactor [TFTR], DIII-D, joint European torus [JET], JT-60U) windows do in fact survive for 5-60-s periods, with similar plasma parameters as TPX, one can be 
confident that instantaneous ablation is not usually a problem. Flux levels at the windows will depend on the power transmitted to the plasma and may reach $40 \mathrm{~W} / \mathrm{cm}^{2}$ at an input power level of $45 \mathrm{MW}$ with values of $15-20 \mathrm{~W} / \mathrm{cm}^{2}$ at an input power level of 18 MW (Ref. 5).

\section{WINDOW MATERIAL PROPERTIES}

Properties of the window materials considered are given in Table 4.1 (Refs. 6-9). Rupture modulus values are used in determining the allowable levels of thermally induced stresses in the window materials.

None of the window materials considered has significant transmittance for wavelengths shorter than $0.1 \mu \mathrm{m}$. Using the definition of cutoff frequency from The Infrared Handbook (Ref. 6) (a transmittance of 10\% through a 2-mm thickness) at the listed cutoff frequency, $90 \%$ of the incident energy is deposited in the first millimeter of window thickness. The incident energy for the extremely short wavelength radiation expected for the TPX application may be considered as a first-surface deposition. The corresponding energy dissipation in a zero-length window will be the first-wall incident energy flux of $40 \mathrm{~W} / \mathrm{cm}^{2}$ at a plasma input power level of $45 \mathrm{MW}$, with values of 15-20 $\mathrm{W} / \mathrm{cm}^{2}$ at a plasma input power level of $18 \mathrm{MW}$. Reduction of energy dissipation levels by transmission through the window materials will be negligible.

Table 4.1. Window Material Properties

\begin{tabular}{|c|c|c|c|c|c|c|c|}
\hline Material & $\begin{array}{c}\text { Modulus } \\
\left(\mathrm{N} / \mathrm{cm}^{2}\right)\end{array}$ & $\begin{array}{l}\text { Coefficient of } \\
\text { Expansion } \\
\left(\times 10^{-6} / \mathrm{K}\right)\end{array}$ & $\begin{array}{l}\text { Density } \\
\left(\mathrm{g} / \mathrm{cm}^{3}\right)\end{array}$ & $\begin{array}{c}\text { Specific } \\
\text { Heat } \\
(\mathrm{J} / \mathrm{g}-\mathrm{K})\end{array}$ & $\begin{array}{c}\text { Conductivity } \\
\text { (W/cm-K) }\end{array}$ & $\begin{array}{c}\text { Rupture } \\
\text { Modulus } \\
\left(\mathrm{N} / \mathrm{cm}^{2}\right)\end{array}$ & $\begin{array}{c}\text { Diffusivity } \\
\left(\mathrm{cm}^{2} / \mathrm{s}\right)\end{array}$ \\
\hline Quartz & 7.32 & 0.56 & 2.21 & 0.741 & 0.014 & 5000 & 0.008 \\
\hline $\mathrm{ZnSe}$ & 6.72 & 7.57 & 5.27 & 0.343 & 0.182 & 5500 & 0.101 \\
\hline $\mathrm{CaF}_{2}$ & 9.86 & 22.3 & 3.18 & 0.854 & 0.081 & 3650 & 0.036 \\
\hline $\mathrm{MgF}_{2}$ & 11.45 & 11.9 & 3.18 & 0.84 & 0.15 & & 0.06 \\
\hline
\end{tabular}

\section{CALCULATED WINDOW TEMPERATURES AND STRESSES FOR TPX WINDOWS COOLED BY STRUCTURAL HEAT SINKING ONLY}

\subsection{Window Temperatures}

An initial scoping of the TPX window problem was accomplished by considering a one-dimensional edge-cooled circular plate with uniform internal-heat generation. This approach is conservative in predicting temperatures and temperature stresses lower than those for the front-surface-loaded, edge-cooled case. If the first-surface heat flux of $40 \mathrm{~W} / \mathrm{cm}^{2}$ is scaled to uniform internal-heat generation by means of the ratio of surface area to volume and the plane surfaces of the window are considered as adiabatic, the resultant temperature distribution is given by

$$
\left.T=F_{o} / 4 k t_{o}\right)\left(R^{2}-r^{2}\right)+T e,
$$


where

$F_{0}=$ surface heat flux $\left(W / \mathrm{cm}^{2}\right)$,

$\mathbf{k}=$ thermal conductivity of window material $\left(\mathrm{W} / \mathrm{cm}-{ }^{\circ} \mathrm{C}\right)$,

$t_{0}=$ window thickness $(\mathrm{cm})$,

$\mathrm{R}$ = outside radius of window,

$\mathrm{T}_{\mathrm{e}}=$ edge temperature of window (assumed as structural temperature, $65^{\circ} \mathrm{C}$ ).

For a 10 -cm-diam, 2-cm-thick quartz window, the power input will be $3140 \mathrm{~W}$ and the adiabatic temperature rise rate $12.2^{\circ} \mathrm{C} / \mathrm{s}$. The radial heat flux density at the window periphery will be $50 \mathrm{~W} / \mathrm{cm}^{2}$. The corresponding temperature gradient in the quartz $\left(\mathrm{k}=0.014 \mathrm{~W} / \mathrm{cm}-{ }^{\circ} \mathrm{C}\right)$ at the window edge will be $3571{ }^{\circ} \mathrm{C} / \mathrm{cm}$, and if the surrounding structure is assumed to be stainless steel $\left(\mathrm{k}=0.17 \mathrm{~W} / \mathrm{cm}-{ }^{\circ} \mathrm{C}\right)$, the radial gradient in the structure at the window edge will be $294^{\circ} \mathrm{C} / \mathrm{cm}$.

It is apparent from this example that edge cooling of large quartz windows will not be possible at these incident radiation flux levels. The other window materials of interest have higher values of conductivity than quartz; however, the window centerline temperatures will generally be excessive for the larger windows for any of the window materials considered. Table 5.1 presents a summary of calculated window edge-tocenterline temperature differences for the four window materials of general interest for TPX diagnostic apertures. The temperatures have been calculated for the five window geometries cited in the Ellis analysis (Appendix A). It is apparent from the tabulated values that edge-cooled windows larger than a few centimeters in diameter are not feasible in any of the materials cited.

The generic case of window temperature as a function of window diameter for a constant (10:1) ratio of widow thickness to diameter (Ref. 10) is shown in Fig. 5.1 for the materials of interest. Diameter limits for a peak window temperature of $400^{\circ} \mathrm{C}$ are indicated, assuming a window edge temperature of $150^{\circ} \mathrm{C}$. This is the standard-designpoint, window-material temperature limit cited for TPX diagnostics.

\begin{tabular}{|c|c|c|c|c|c|}
\hline \multirow{2}{*}{$\begin{array}{l}\text { Window } \\
\text { Material }\end{array}$} & \multicolumn{5}{|c|}{ Window Diameter/Thickness (cm) } \\
\hline & $1.8 / 0.71$ & $3.81 / 1.73$ & $6.83 / 1.73$ & $10.16 / 1.98$ & $15.57 / 2.21$ \\
\hline Quartz & 815 & 1486 & 4790 & 9360 & 19703 \\
\hline $\mathrm{ZnSe}$ & 62.7 & 114.5 & 369 & 695 & 1518 \\
\hline $\mathrm{CaF}_{2}$ & 142 & 258 & 832 & 1565 & 3422 \\
\hline $\mathrm{MgF}_{2}$ & 76 & 139 & 447 & 840 & 1836 \\
\hline
\end{tabular}




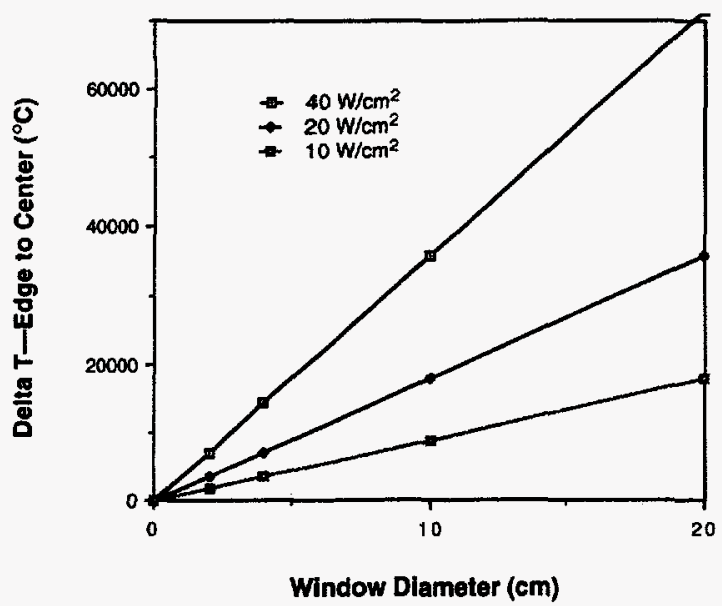

WINDOW TEMPERATURE DIFFERENCE VB DIAMETER-CaF,

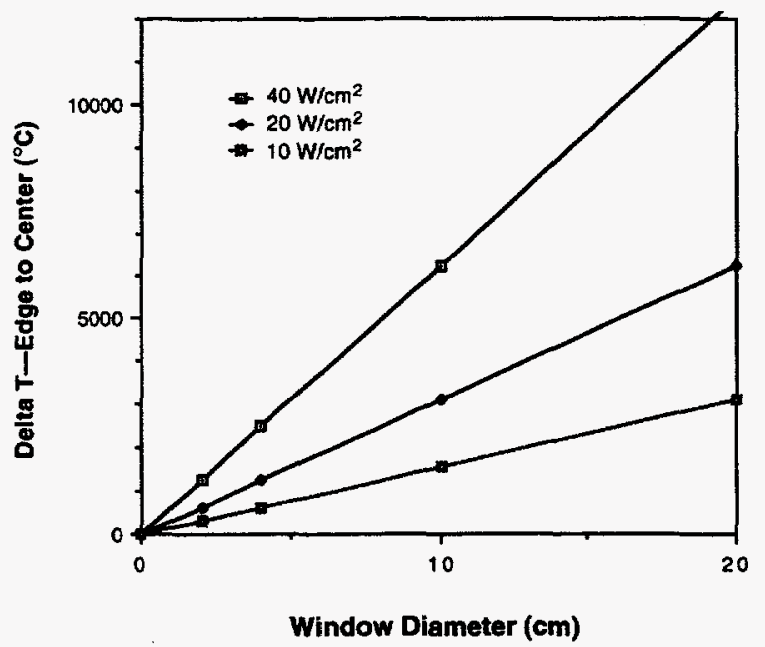

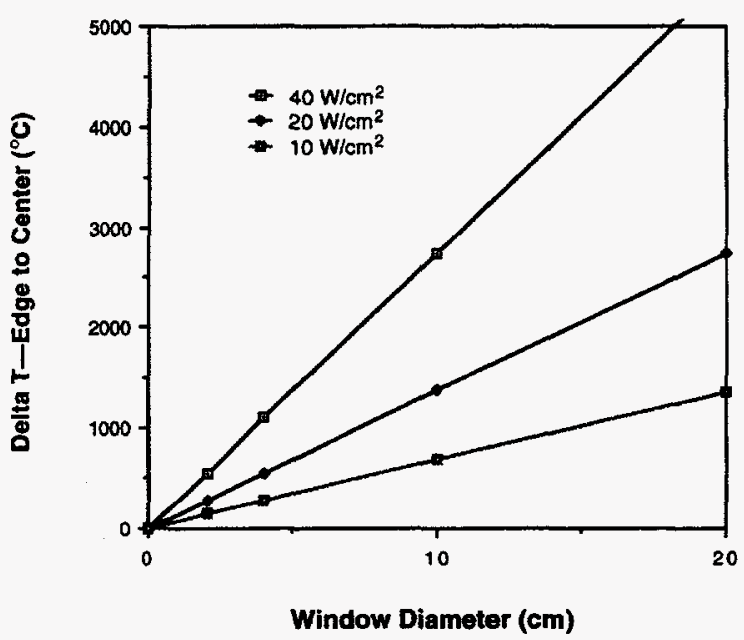

WINDOW TEMPERATURE DIFFERENCE v 8 DIAMETER-MgF 2

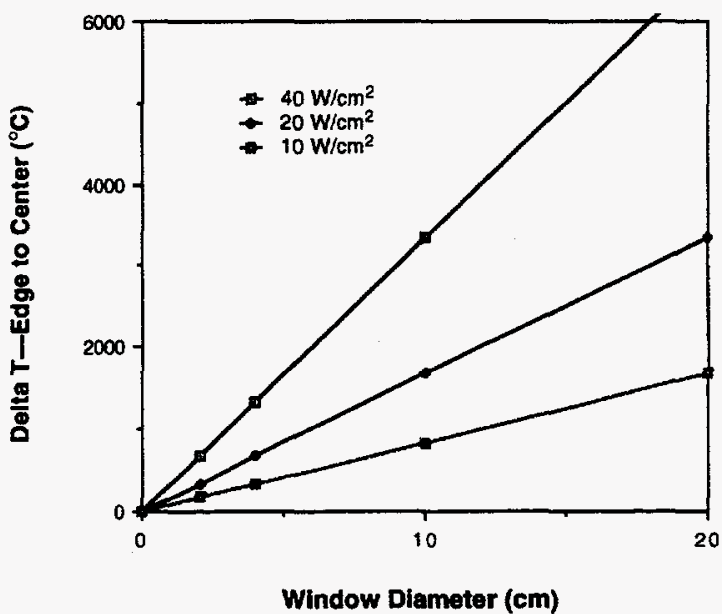

Fig. 5.1. $\triangle T$ in TPX windows for various materials and incident flux levels.

\subsection{Window Stresses}

Thermal stresses in the windows have been calculated for the case of a free window edge. That is, the periphery of the windows is assumed to be unconstrained by the surrounding structure and free to expand thermally. The calculated stresses are internal to the window and are the result of the internal temperature gradients. For a symmetrically heated disk with $T=f(r)$ only and a free outer edge, the radial stress will be given by the following (Ref. 11):

$$
\sigma_{\mathrm{r}}=\alpha \cdot \mathrm{E} \cdot\left(\frac{1}{\mathrm{R}^{2}} \int_{0}^{\mathrm{R}} \mathrm{T} \cdot \mathrm{rdr}-\frac{1}{\mathrm{r}^{2}} \int_{0}^{\mathrm{r}} \mathrm{T} \cdot \mathrm{wdw}\right)
$$


and the tangential stress by

$$
\sigma_{\mathrm{t}}=\alpha \cdot \mathrm{E} \cdot\left(-\mathrm{T}+\left(\frac{1}{\mathrm{R}^{2}} \int_{0}^{\mathrm{R}} \mathrm{T} \cdot \mathrm{rdr}-\frac{1}{\mathrm{r}^{2}} \int_{0}^{\mathrm{r}} \mathrm{T} \cdot \mathrm{wdw}\right)\right),
$$

where

$$
\begin{aligned}
& \mathrm{a}=\text { thermal diffusivity, } \\
& \mathrm{E}=\text { modulus of elasticity, } \\
& \mathrm{R}=\text { outside radius of disk, } \\
& \mathrm{T}=\mathrm{T}(\mathrm{r})-\mathrm{T}_{\mathrm{o}}
\end{aligned}
$$

and a negative sign indicates compression.

The peak stresses tabulated are compressive. The ultimate failure of the windows from thermally induced stresses will be as a result of the tensile stress in the periphery of the window in the radially unconstrained edge case. However, as the tabulated values indicate, the peak compressive stresses are also well above practical limits for the materials. The use of more exact finite-element models is necessary for more accurate stress determinations under the combined pressure and thermal loads. However, these calculated values are conservative and may be evaluated in terms of the rupture moduli of the window materials. Table 5.2 provides a listing of peak radial stresses for the same window diameters and thicknesses used in Table 5.1.

A generic plot of window thermal stress versus diameter for a constant diameter-tothickness ratio of 10 is given in Fig. 5.2, with the rupture modulus values indicated by the lines at different power levels. It may be concluded from these data that edgecooled, direct-exposure windows larger than a few centimeters in diameter will not survive the TPX environment.

Table 5.2. Peak Thermal Stress (psi) in Edge-Cooled Windows for the Case of $40 \mathrm{~W} / \mathrm{cm}^{2}$ Heat Flux

\begin{tabular}{lccccc}
\hline Window & \multicolumn{5}{c}{ Window Diameter/Thickness (cm) } \\
\cline { 2 - 6 } Material & $\mathbf{1 . 8 / 0 . 7 1}$ & $\mathbf{3 . 8 1 / 1 . 7 3}$ & $\mathbf{6 . 8 3 / 1 . 7 3}$ & $\mathbf{1 0 . 1 6 / 1 . 9 8}$ & $\mathbf{1 5 . 5 7 / 2 . 2 1}$ \\
\hline Quartz & 1210 & 2202 & 7117 & 3936 & 29300 \\
ZnSe & 1155 & 2102 & 6795 & 13289 & 27966 \\
$\mathrm{CaF}_{2}$ & 11225 & 20430 & 66008 & 129098 & 271666 \\
$\mathrm{MgF}_{2}$ & 3755 & 6834 & 22082 & 43188 & 90833 \\
$\mathrm{Si}$ & 272 & 496 & 1602 & 3134 & 6597 \\
\hline \hline
\end{tabular}




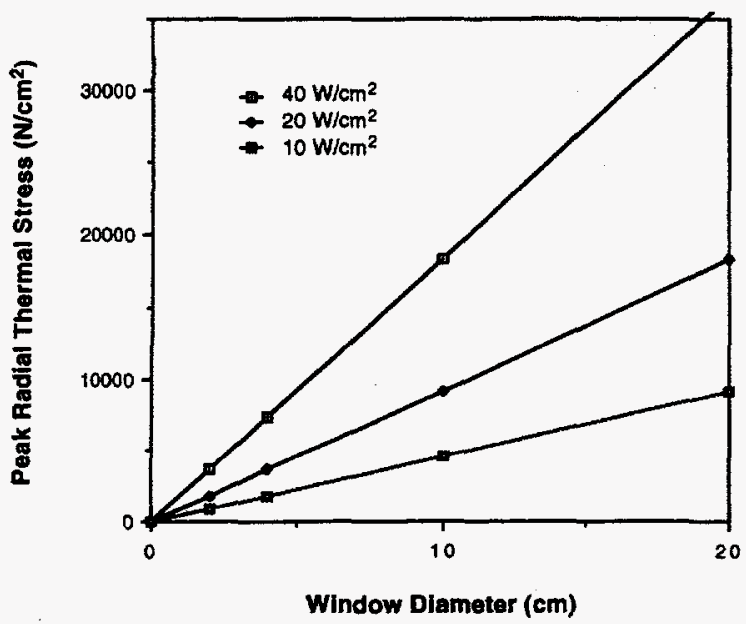

PEAK RADIAL THERMAL STRESS vs DIAMETER-CaF

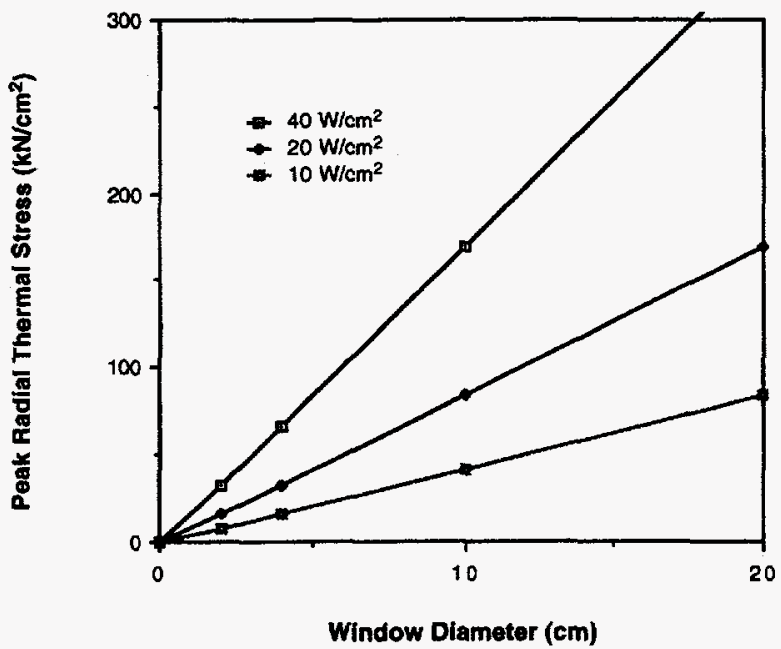

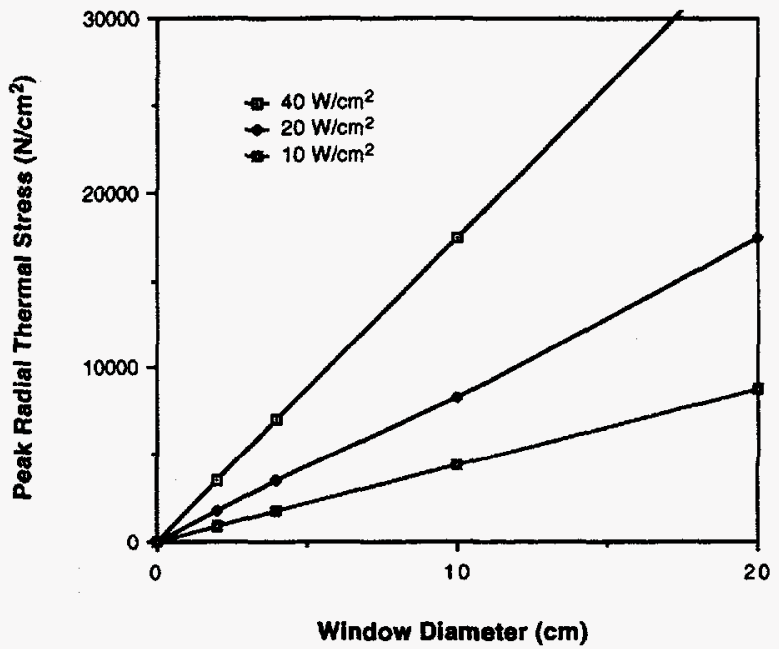

PEAK RADIAL THERMAL STRESS v8 DIAMETER-MgF,

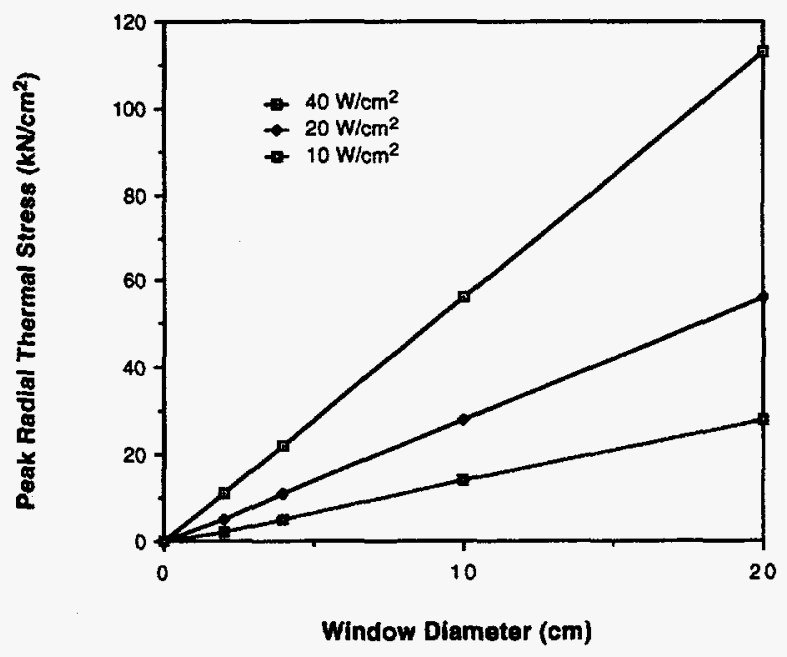

Fig. 5.2. Thermal stress in TPX windows for various materials and incident flux levels.

The stress in a window resulting from pressure loading, considering it as a uniformly loaded, edge-supported circular plate, is given by the following (Ref. 11):

$$
\max \sigma_{\mathrm{r}}=\sigma_{\mathrm{t}}=\left(3 \mathrm{~W} / 8 \pi \mathrm{m} \mathrm{t}^{2}\right)(3 \mathrm{~m}+1),
$$

where

$$
\begin{aligned}
& \sigma_{\mathrm{r}}=\text { radial stress at center, } \\
& \sigma_{\mathrm{t}}=\text { tangential stress at center, } \\
& W=\text { total load on plate, } \\
& \mathrm{m}=\text { reciprocal of Poisson's ratio, } \\
& \mathrm{t}=\text { thickness of plate. }
\end{aligned}
$$


For a Poisson's ratio of 0.2 , typical of window materials, and a differential pressure loading of one atmosphere,

$$
\max \sigma_{\mathrm{r}}=18 \mathrm{r}^{2} / \mathrm{t}^{2}\left(\mathrm{lb} / \mathrm{in}^{2}\right)
$$

Assuming a thickness-to-diameter ratio of 0.1 ,

$$
\max \sigma_{\mathrm{r}}=450 \mathrm{lb} / \mathrm{in}^{2}
$$

approximately an order of magnitude below the rupture modulus of typical window material. If the edge is clamped, the maximum stress will be lower by approximately one-third. It may be concluded that the critical stress for the windows will be established by thermally induced distortion in most cases.

\section{REVIEW OF RELATED WINDOW-COOLING TECHNOLOGY}

It may be concluded from the above that any window more than 1 or $2 \mathrm{~cm}$ in diameter will require some sort of shielding or cooling when it is exposed to the incidentradiation flux levels expected in TPX. A review of window protection techniques used in other fields is therefore in order. Fields considered include lasers, endoatmosphericmissile infrared (IR) windows, and microwave gyrotrons. In addition, cooling techniques used in semiconductor-electronic-substrate applications were reviewed.

\subsection{Laser Window-Cooling Technology}

The operational limits of high-power-laser windows have been the subject of a number of prior investigations (e.g., Refs. 12-16). Typically, the instantaneous exposure levels for laser application are higher than those expected for the TPX application, but the exposure durations are much shorter. Even for $\mathrm{CW}$ laser applications the run times for a discrete exposure are typically approximately a few seconds with the windows seldom reaching thermal steady state during the exposure period. Transient thermal response is a major concern with allowable flux levels frequently established by the thermal stress induced in the windows during the transient. Table 6.1, abstracted from Ref. 13, gives calculated absorbed-flux-density limits for laser window materials of interest exposed to a 1-s CW laser pulse duration. The limits are established by the predicted failure of the window as a result of thermal shock. The incident energy is assumed to be uniformly dissipated through the window, and the window is considered thick enough to allow one-dimensional modeling to be used. The diameter of the window is consequently not a concern in the calculations, given that the aperture is considered to be completely filled. It is of interest that the absorbed failure-level flux density for many of the materials is less than the steady-state level expected in TPX. The windows considered in this analysis are uncooled; however, given the 1-s exposure duration and one-dimensional model assumptions, the use of edge or face cooling would not significantly alter the results. 
Table 6.1. Absorbed-Flux-Density Limits: 1-s CW Laser Run Time ${ }^{\mathrm{a}}$

\begin{tabular}{|c|c|c|c|}
\hline $\begin{array}{l}\text { Window } \\
\text { Material }\end{array}$ & $\begin{array}{c}\text { Absorbed } \\
\text { Flux Density } \\
\left(\mathrm{W} / \mathrm{cm}^{2}\right)\end{array}$ & $\begin{array}{c}\text { Minimum } \\
\text { Thickness } \\
\text { (cm) } \\
\end{array}$ & $\begin{array}{c}\text { Delta } \\
T_{\text {shock }} \\
\left({ }^{\circ} \mathrm{C}\right) \\
\end{array}$ \\
\hline Quartz & 196 & 0.646 & 1482.0 \\
\hline $\mathrm{ZnSe}$ & 26 & 2.198 & 73.0 \\
\hline $\mathrm{CaF}_{2}$ (poly) & 55 & 1.341 & 120.0 \\
\hline $\mathrm{MgF}_{2}$ (single) & 22 & 1.664 & 27.39 \\
\hline
\end{tabular}

In laser window applications a common method of cooling is by clamping a coolant channel to the edge of the window. This technique is of use primarily in the case of small-diameter windows of high-conductivity materials and has been shown above to be of comparatively little use in the case of large-diameter $(>2-4 \mathrm{~cm})$ windows of a lowconductivity material such as quartz.

Face cooling of laser windows by using optically transparent coolants has been investigated. In Ref. 15, for example, helium gas was used as a window coolant for a large spherical, fused-silica window ( $65 \mathrm{~cm}$ in diameter, $0.5 \mathrm{~cm}$ thick), with the gas injected axially and removed radially. Surface heat transfer coefficients of $280 \mathrm{~W} / \mathrm{m}^{2 \circ} \mathrm{C}$ were predicted with gas velocities of $305 \mathrm{~m} / \mathrm{s}$. The window transmitted a 1-MW laser beam with an assumed power absorption $100 \mathrm{ppm}$ per surface and $30 \mathrm{ppm}$ in bulk. Response time constant for the window was $30 \mathrm{~s}$ with steady state reached in about $200 \mathrm{~s}$.

Heat pipe cooling has been used in laser mirror applications and proposed for laser window use. The demonstrated heat-transfer coefficients claimed range to $10^{5} \mathrm{~W} / \mathrm{m}^{2 \circ} \mathrm{C}$ (Ref. 16). In TPX application of this concept, the vapor channel of the heat pipe would have to be an interior cavity in the window.

\subsection{Endoatmospheric Missile Window-Cooling Technology}

Several IR window-cooling concepts intended for use at thermal flux levels comparable to those anticipated for TPX concepts have been investigated for endoatmospheric missile interceptors. For example, Los Alamos led a concept definition study for a hypervelocity $(6-10 \mathrm{~km} / \mathrm{s})$ endoatmospheric interceptor with extreme thermal loading requirements (Ref. 17). Thermal protection methods employed included external film cooling, internal single-phase microchannel cooling, internal and vented phase-change cooling and micro-heat-pipe cooling. One of the most technically verified concepts is a film-cooled sapphire window being developed by McDonnell Douglas Aerospace (Refs. 18, 19). This window utilizes a slot-injected coolant gas, typically helium, to 
maintain a barrier between the external flow environment and the window surface. The concept has undergone several full-scale tests combining measurements of cooling effectiveness and aerooptic performance with helium and $\mathrm{N}_{2} \mathrm{O}_{4}$ coolants. However, the gas-film-cooling concepts are not readily applicable to the TPX system. For a radiantly heated window, the gas shielding is ineffective and incompatible with vacuum operation if it is applied to the heated surface. The internal cooling techniques under development by other contractors are of more interest for TPX applications.

Lockheed is developing an internally cooled window based on diamond-coated silicon (Refs. 20,21). This window is an attempt to combine the desirable features of diamond (high-thermal-conductivity and strength characteristics) and silicon (high IR transmission, easily etched) with the weight savings realized from the use of an efficient liquid coolant (water). This concept employs single-phase microchannel cooling and provides high heat-transfer capability and low temperature differences in the window structure. This approach is attractive in that it is based on a closed, single-phase cooling system integrated with the window and provides high heat-transfer coefficients.

Loral Vought Systems Corporation is developing a two-phase cooled silicon window (Ref. 22). Ammonia coolant boils up through laser-machined channels in a silicon substrate, vaporizes near the top (porous) cover, and is vented as a gas. The ammonia coolant is attractive in that it is stored as a liquid and has a low boiling point, high latent heat, and low absorption in the IR. Limited test data exist for this concept and a fullscale model has yet to be built. In TPX application of this concept, the vapor would have to be vented to an interior cavity in the window rather than at the front surface.

An alternative missile-window-cooling system involves the integration of microheat pipes embedded in the IR window or fabricated from the window material. This system is intended to provide a passive alternative to a pumped single-phase or twophase system. Micro-heat-pipe cooling uses a liquid-vapor phase change, so it retains the mass advantages of two-phase systems. It also offers potentially significant mass savings over the pumped two-phase system. Being passive, an embedded micro-heatpipe cooling system is inherently more reliable than pumped systems. The micro-heat pipes would consist of small channels spaced across the window so that the working fluid vapor would not attenuate the IR signal. Some loss of aperture area would be involved.

\section{DEVELOPMENT OF TPX DIAGNOSTIC WINDOW-COOLING CONCEPT}

The approach to window cooling for TPX will depend on the required window aperture and material. Windows in comparatively high-conductivity materials such as $\mathrm{MgF}_{2}$ may be edge-cooled at diameters of about $2 \mathrm{~cm}$. Quartz windows and largerdiameter windows in most other materials will require more complex thermal management systems. Some of the candidate thermal control methods are discussed in the following paragraphs. 


\subsection{Attenuation of Window Radiation Loads by Re-entrant Mirrors}

The surface heat flux levels expected in the TPX $\left(40 \mathrm{~W} / \mathrm{cm}^{2}\right)$, although very high for windows, are well within the range of demonstrated performance for mirror systems used in high-power CW laser systems. Internally cooled metal laser mirrors using microchannel, powder metal, or screen heat-exchange surfaces have demonstrated thermal capability in the $200 \mathrm{~W} / \mathrm{cm}^{2}$ range or higher (Ref. 23). Because most of the incident energy in the TPX application is at very short wavelengths $(90 \%<40 \AA$ ), frequency selective reflection from the mirror surfaces will be inherent and the vacuum window incident energy may be reduced to a few $\mathrm{W} / \mathrm{cm}^{2}$. Problems in implementation of this approach will involve routing coolant to the mirrors and maintaining reasonable reflectance of the mirror surfaces at the diagnostic-sensor wavelengths without maintenance. If mirrors are required for other reasons such as scanning within the vacuum envelope, they would be the choice for thermal isolation of the corresponding vacuum windows.

\subsection{Use of High-Thermal-Conductivity Window Coating}

If the conductivity of the vacuum surface layer of the window could be increased sufficiently, it would be possible to use edge cooling of the windows at diameters as large as $10-15 \mathrm{~cm}$. Because the windows are essentially opaque at the predominantincident-energy wavelengths, the deposition of energy in the window is a surface effect and could be handled in a comparatively thin, high-conductivity layer. The use of highconductivity, transparent films of diamond on the substrate of the structural window has been proposed for microwave gyrotrons (Ref. 14), as well as for a variety of other highpower applications (Refs. 24-26). A similar approach is considered here. Roomtemperature values of thermal conductivity of deposited diamond films approach $24 \mathrm{~W} / \mathrm{cm}^{2}-\mathrm{K}$. At an incident radiation flux level of $40 \mathrm{~W} / \mathrm{cm}^{2}$ on a $10-\mathrm{cm}$ window, a diamond film thickness of about $1 \mathrm{~mm}$ would provide an edge-to-center temperature difference of about $105^{\circ} \mathrm{C}$, an acceptable value. This diamond film thickness is within the range of deposition techniques for small-area deposits, although not currently possible for multicentimeter-sized windows. The use of a deposited diamond coating combined with window edge cooling by conduction through the supporting structure to a liquid-coolant channel would be an attractive solution to the TPX window problems if the coating technology for larger apertures were available. The present technology limit is an approximately 1 -cm diameter for high-optical-quality material.

\subsection{Increased Window Conductance by Micro-Heat Pipe}

A second method of increasing the apparent thermal conductivity of the window would be to incorporate a passive, phase-change heat-transfer system internal to the window through the use of micro-heat-pipe technology. Implementation would involve etching fluid channels in the window surface and sealing the channels with a surface 
layer of transparent material (of the same type as the base material). This technique has been demonstrated in silicon for semiconductor applications and could be implemented in quartz or sapphire. In prior investigations improvements in apparent thermal conductivity of about an order of magnitude have been demonstrated (Ref. 27). In the interests of isothermality, the technique might be modified to incorporate fluid supply channels coupled to a low-axial-pressure-drop vapor-space in order to improve the apparent conductivity and increase the allowable channel length and consequent window diameter. The fluid or vapor used in a vapor chamber system would have to be transparent at the diagnostic-sensor wavelength at least in the vapor state, and the vapor pressure at the operational temperature would have to be low enough to minimize mechanical loads on the thin front surface window. The present capabilities and limitations of micro-heat pipes are summarized in Table 7.1.

In the implementing of micro-heat pipes, a fraction of the window surface area is blocked by the heat pipes. If the heat pipe cavities are rectangular with the small dimension parallel to the heated surface and the large dimension perpendicular to the heated surface, blockage will be minimized. If the heated surface area, $A_{\text {surface }}$ is treated as rectangular and the heat pipe cross sectional area is $A_{a x i a l}=N \cdot b \cdot h$, then substituting the expression for $\mathrm{N}$ into the $\mathrm{A}_{\text {axial }}$ expression and dividing into $\mathrm{A}_{\text {surface }}$ gives the surface-to-axial area ratio

$$
A_{\text {surface }} / A_{\text {axial }}=L /[B \mathrm{~h}] \text {, }
$$

Table 7.1. Capabilities and Limitations of Micro-Heat Pipes

\begin{tabular}{|c|c|c|c|}
\hline Parameter & Symbol & Target & Comments \\
\hline Window blockage factor & B & $<0.2$ & $\begin{array}{l}\text { Area covered by heat } \\
\text { pipe/total window area }\end{array}$ \\
\hline $\begin{array}{l}\text { Surface heating rate } \\
\text { per unit area }\end{array}$ & $\mathrm{q"}_{\text {surface }}$ & $\sim 50 \mathrm{~W} / \mathrm{cm}^{2}$ & $\begin{array}{l}\text { Higher values } \\
\text { demonstrated for } \\
\text { small areas }\end{array}$ \\
\hline $\begin{array}{l}\text { Heat pipe length to } \\
\text { hydraulic diameter }\end{array}$ & $\mathrm{L} / \mathrm{D}_{\mathrm{h}}$ & $<200$ & $\begin{array}{l}\text { Related to capillary limit } \\
\text { calculation }\end{array}$ \\
\hline $\begin{array}{l}\text { Heat pipe capillary } \\
\text { limited heat flux }\end{array}$ & $q_{\text {cap }}^{\prime \prime}$ & $<3000 \mathrm{~W} / \mathrm{cm}^{2}$ & \\
\hline $\begin{array}{l}\text { Heat pipe sonic } \\
\text { limited heat flux }\end{array}$ & $\mathrm{q}_{\text {sonic }}$ & $\begin{array}{l}<20000 \mathrm{~W} / \mathrm{cm}^{2} \\
\text { (ammonia @ } 325 \mathrm{~K} \text { ) }\end{array}$ & $\begin{array}{l}\text { Target value strongly } \\
\text { temperature dependent }\end{array}$ \\
\hline $\begin{array}{l}\text { Heat pipe radial boiling } \\
\text { limited heat flux }\end{array}$ & $\mathrm{q}_{\text {dryout }}^{\prime \prime}$ & $<100 \mathrm{~W} / \mathrm{cm}^{2}$ & $\begin{array}{l}\text { Based on heat pipe } \\
\text { evaporator wall area }\end{array}$ \\
\hline
\end{tabular}


where

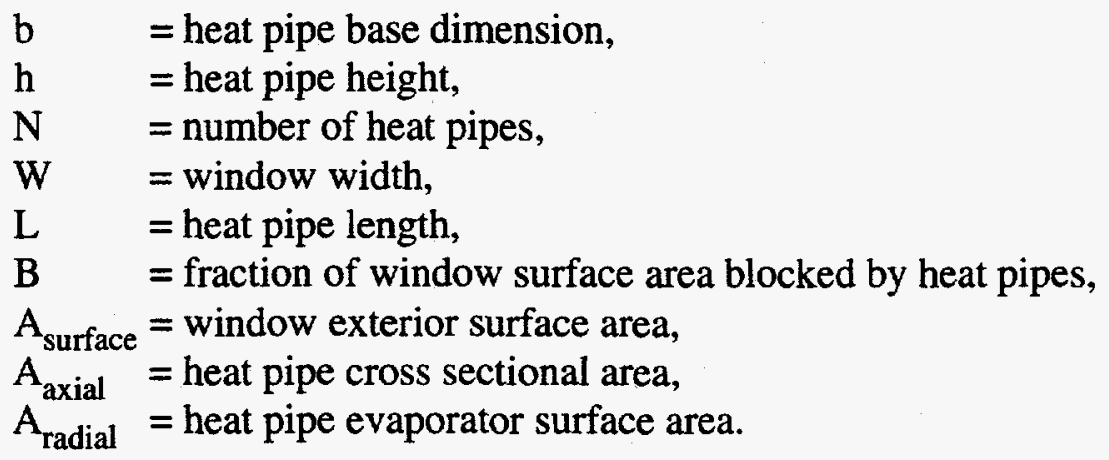

A plot of $A_{\text {surface }} / A_{\text {axial }}$ versus the window blockage factor with typical micro-heatpipe aspect ratios as a parameter is given in Fig. 7.1.

For this application the heat pipe working fluid is selected according to its heat transport capacity within the expected window temperature range of $350-400 \mathrm{~K}$. Between 300 and $450 \mathrm{~K}$, water and ammonia are commonly used according to their high heat-transport capacity and compatibility with typical containment materials. The transport of water or ammonia vapor in this temperature range is limited by the pressure head that can be developed by the heat pipe capillary structure. The capillary-limited heat flux for typical wick structures with water or ammonia is around $3000 \mathrm{~W} / \mathrm{cm}^{2}$. The allowable heat flux at the IR window surface is then

\section{IR Window Axial Heat Flux Factors}

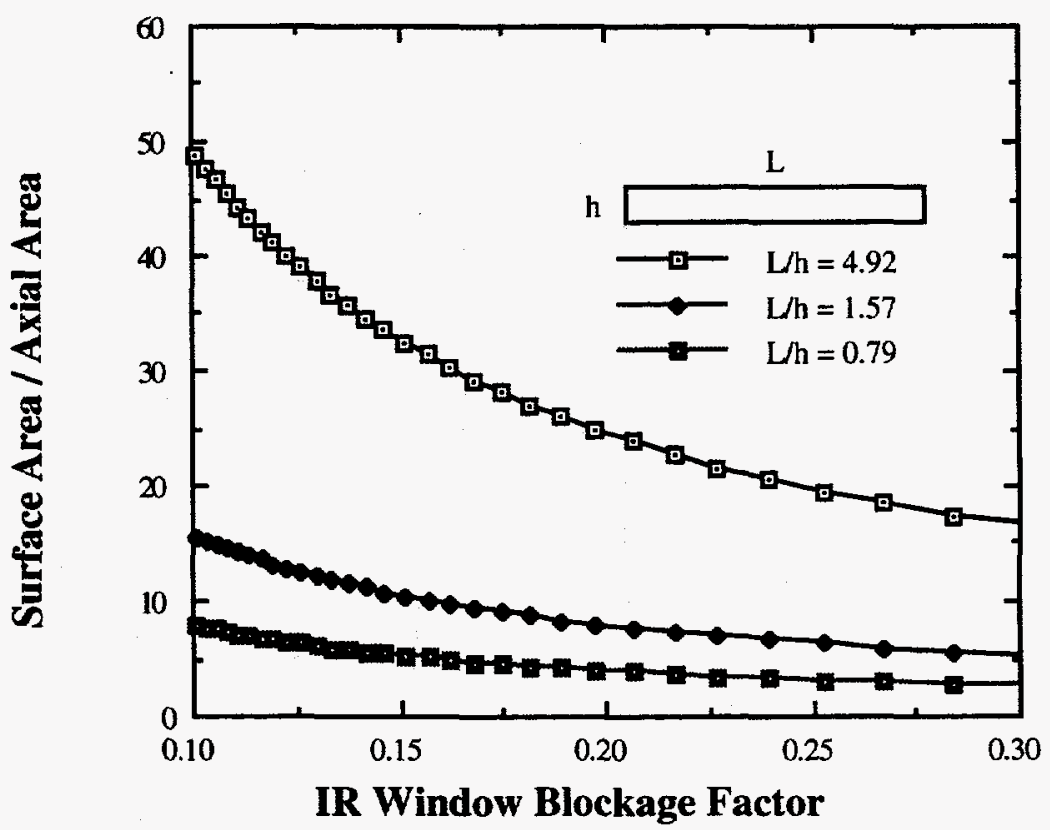

Fig. 7.1. Axial/surface area ratio versus the window blockage factor. 


$$
\mathrm{q}_{\text {surface }}<\mathrm{q}_{\text {capillary }} \mathrm{A}_{\text {axial }} / \mathrm{A}_{\text {surface }} \text {. }
$$

A plot of $\mathrm{q}_{\text {" }}$ surface versus the window blockage factor with heat pipe length-to-height ratios as a parameter is given in Fig. 7.2. The plot indicates that characteristic TPX heating rates can be achieved in heat pipes with a length-to-height ratio of 1 and a blockage factor of 0.1 . This corresponds to a configuration where the heat pipes are placed radially with shorter heat pipes filling the outer areas.

The fraction of the window surface that is blocked by the heat pipes is $B=b \cdot N / W$. The total number of heat pipes for a given blockage factor is then $N=B \cdot W / b$. Since the heated surface area is $A_{\text {surface }}=L \times W$ and the area per unit depth of the heat pipe perimeter is $A_{\text {radial }}=2(h+b) N L$, then substituting the expression for $N$ into the $A_{\text {radial }}$ and dividing by $A_{\text {surface }}$ gives the ratio of the length of the heat pipe perimeter to the area of the heated surface on the IR window:

$$
A_{\text {surface }} / A_{\text {radial }}=b /[2(h+b) B] .
$$

\section{Surface Heat Flux-Capillary Limit Relation}

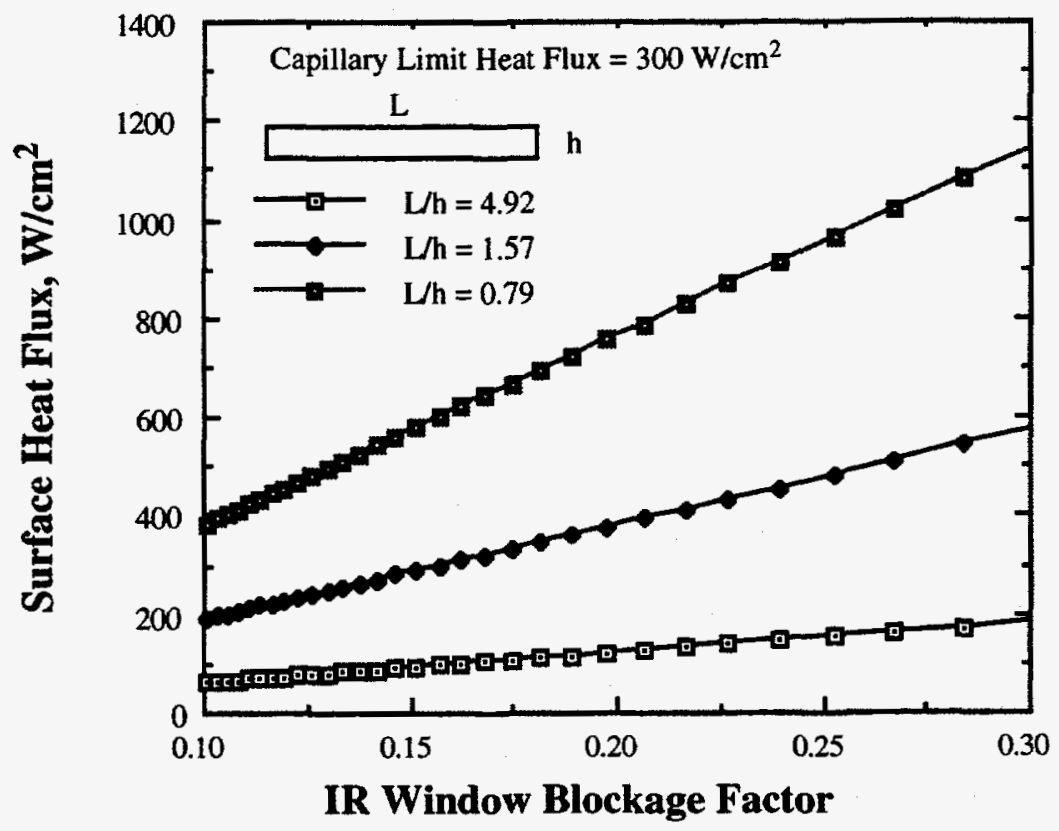

Fig. 7.2. $q^{\prime \prime}$ surface versus the window blockage factor with heat pipe length-to-height ratios as a parameter. 
A plot of $A_{\text {surface }} / A_{\text {radial }}$ versus the window blockage factor with typical micro-heatpipe aspect ratios as a parameter is given in Fig. 7.3.

Another potential limit to heat pipe operation at high heating rates is a dryout of the heat pipe evaporator. A number of correlations exist for the prediction of heat pipe dryout. The presence of a surface-tension-driven capillary structure can increase the dryout heating rate to values much higher than those for ordinary surfaces. Dryout of high-Prandlt-number liquids typically occurs at heat fluxes below $100 \mathrm{~W} / \mathrm{cm}^{2}$. The allowable heat flux at the IR window surface is then

$$
q^{\prime \prime} \text { surface }<q_{\text {dryout }} A_{\text {radial }} / A_{\text {surface }}
$$

A plot of $\mathrm{q}_{\text {"surface }}$ versus the window blockage factor with heat pipe length-to-height ratios as a parameter is given in Fig. 7.4. The plot indicates that the highest heat fluxes are tolerated when the aspect ratio $\mathrm{h} / \mathrm{b}$ is large.

The heat pipe length on the window is constrained by the capillary pumping capacity. For a 2.0 -cm-radius window with a surface heat flux of $50 \mathrm{~W} / \mathrm{cm}^{2}$, heat pipes could be inserted radially to minimize the individual heat pipe length with a shorter heat pipe filling the spaces near the window edge, as indicated schematically in Fig. 7.5.

Using this configuration with individual heat pipe widths of about $100 \mu \mathrm{m}$ and length-to-diameter ratios of $<200$ to 1 , window diameters of $4-5 \mathrm{~cm}$ could be accommodated within the demonstrated capabilities of the existing technology.

\section{IR Window Radial Heat Flux Reduction}

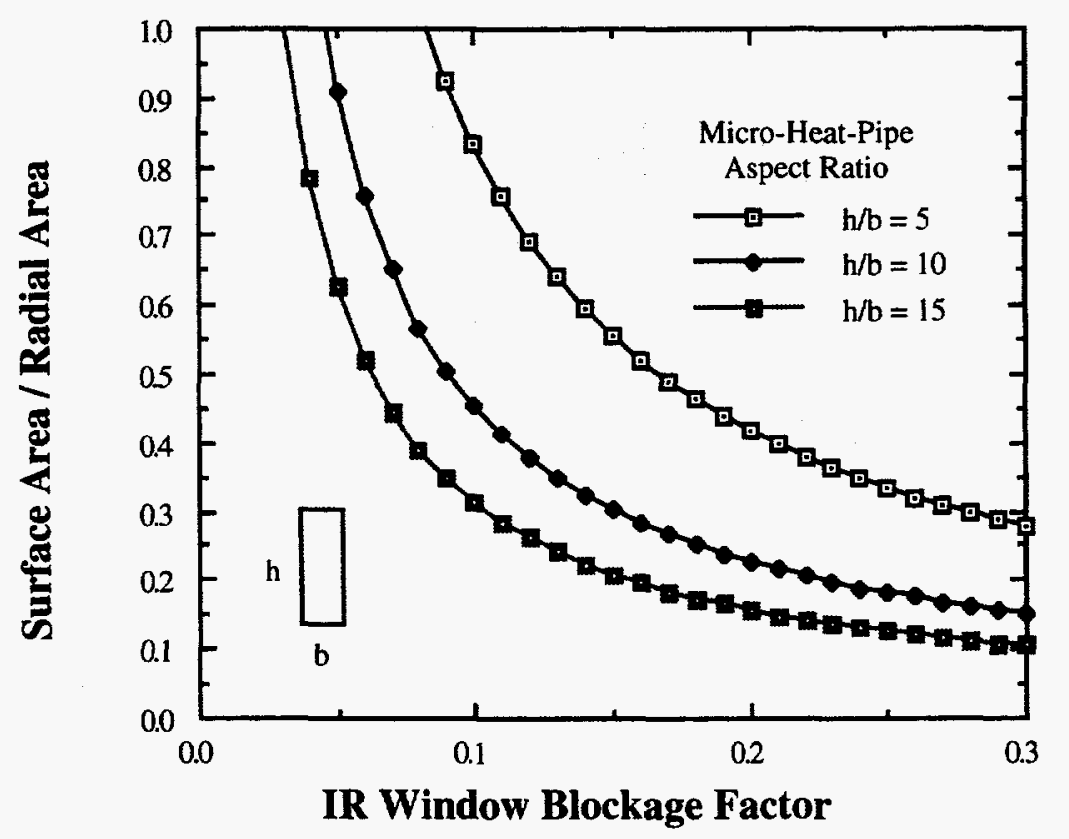

Fig. 7.3. $A_{\text {surface }} / A_{\text {radial }}$ versus the window blockage factor. 


\section{Surface Heat Flux-Boiling Limit Relation}

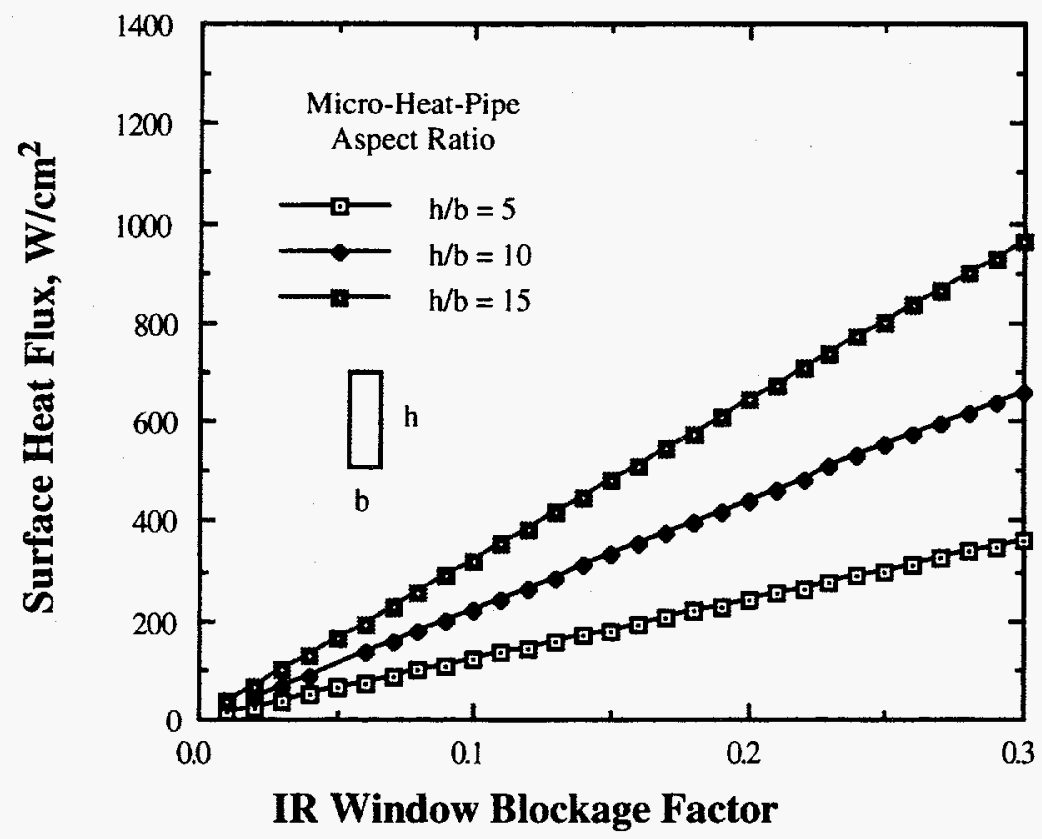

Fig. 7.4. $q^{\prime \prime}$ surface versus the window blockage factor with heat pipe length-to-height ratios as a parameter.

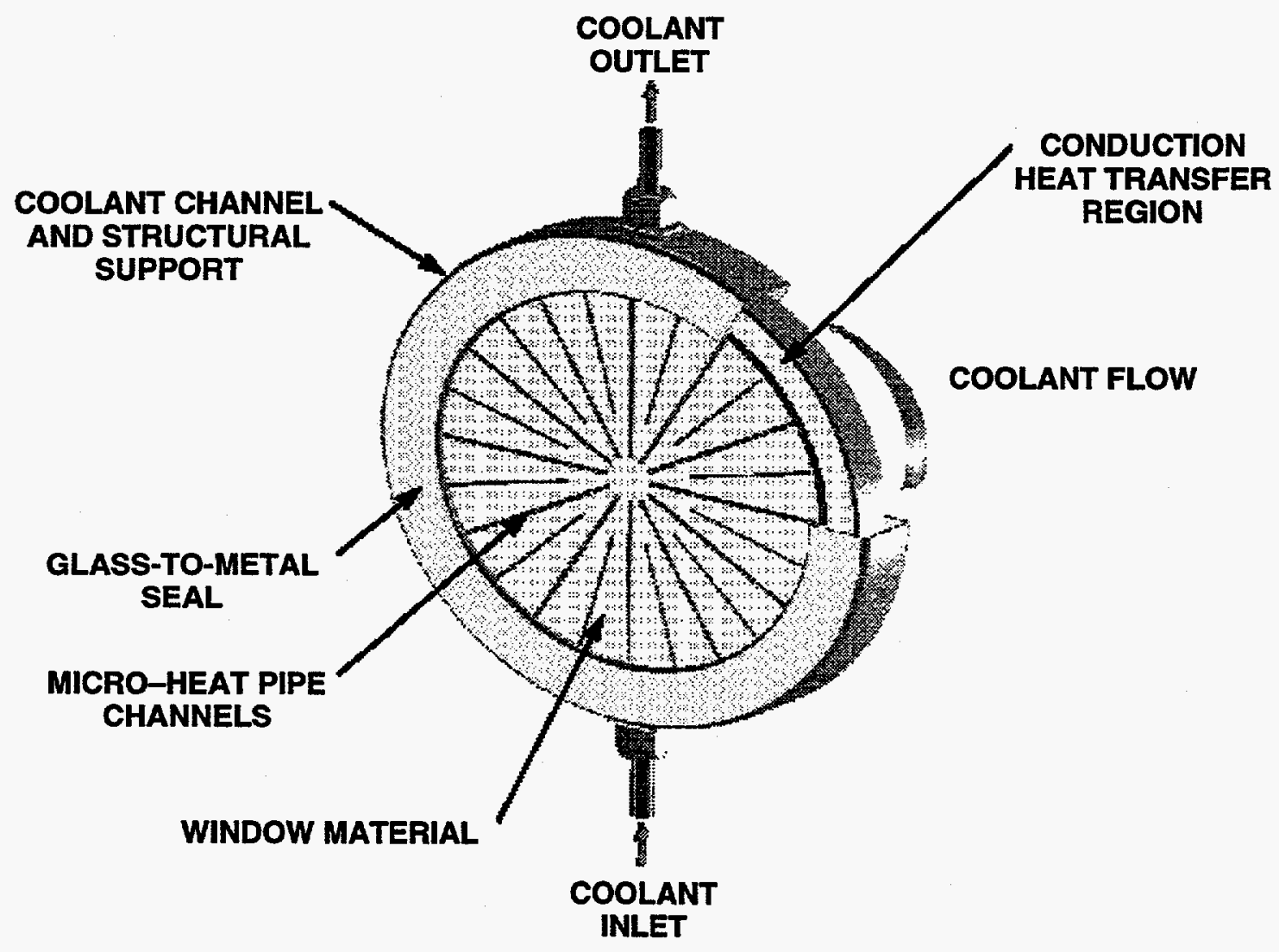

Fig. 7.5. Window cooled by a micro-heat pipe. 


\subsection{Window Surface Cooling (Gas) by Forced Convection}

Face cooling of laser windows has been employed by using optically transparent gaseous or liquid coolants. A comparison of gas and liquid cooling of laser windows in face- and edge-cooling applications is presented in Ref. 28 . In the reference, heattransfer coefficients are calculated for a double-pane $\mathrm{ZnSe}$ window using optimized nitrogen gas cooling. The calculated surface heat-transfer coefficient is $h=0.01$ $\mathrm{W} / \mathrm{cm}^{2 \circ} \mathrm{C}$. In Ref. 15 , cited above, helium gas was used as a window with the gas injected axially and removed radially. Surface heat-transfer coefficients of 0.028 $\mathrm{W} / \mathrm{cm}^{2 \circ} \mathrm{C}$ were achieved with gas velocities of $305 \mathrm{~m} / \mathrm{s}$. Given the use of helium as a coolant and the high gas velocities employed, this example may be viewed as near the ultimate performance limits to be expected for this type of gas cooling. At a flux level of $40 \mathrm{~W} / \mathrm{cm}^{2}$, the corresponding temperature difference between the impinging gas flow and the window surface would be more than $1400^{\circ} \mathrm{C}$. In addition, for a low-conductivity material such as quartz, a significant temperature difference would be incurred in conduction of the heat load from the front to rear surface of the window. In consequence, this method of cooling appears to be of limited value for TPX application.

\subsection{Window Cooling by Internal Forced Convection (Microchannel)}

Microchannel cooling was first proposed for the cooling of semiconductor devices in 1981 (Ref. 29) and investigated further in a doctoral thesis by Tuckerman (Ref. 30) in 1984. Interest in the concept for application in electronic-substrate and laser mirror cooling led to a number of subsequent investigations, including work conducted at Stanford University (Ref. 31), Massachusetts Institute of Technology, North Carolina State University, and Auburn University in the United States. A recent survey of the literature in the field is presented in Ref. 32. The concept exploits the fact that the thermal resistance between a flow passage wall and the cooling fluid temperature decreases with decreasing channel width, providing a means of achieving high values of heat-transfer coefficients and a large heat-transfer area per unit of heated area through the use of very narrow flow passages. Microchannel flow cooling techniques used in laser mirror and semiconductor-electronic-device cooling have been applied to the cooling of IR windows in missile applications by using the same fabrication technology employed in micro-heat pipes (Refs. 20,21). A grid of flow channels is etched directly on the front surface of the window, sealed with a thin surface layer of window material and supplied with coolant from window edge plenums. The configuration is shown schematically in Fig. 7.6 (taken from Ref. 21).

This cooling technique has been experimentally demonstrated with flow channel lengths to $10 \mathrm{~cm}$ (Refs. 29, 30,33-35). Power-handling capability has been demonstrated at levels to about $100 \mathrm{~W} / \mathrm{cm}^{2}$ with measured heat-transfer coefficients of about $5 \mathrm{~W} / \mathrm{cm}^{2} \mathrm{~K}$. Equivalent thermal resistances from the facing surface to the fluid in the flow channel are typically below $0.1^{\circ} \mathrm{C}-\mathrm{cm}^{2} / \mathrm{W}$ for optimized geometries. Commonly, the flow channel widths range from 50 to $100 \mu \mathrm{m}$, with the flow channel spacing determined by the allowable material surface temperatures. A summary of a variety of experimental results is presented in Table 7.2, reproduced from Ref. 36. 


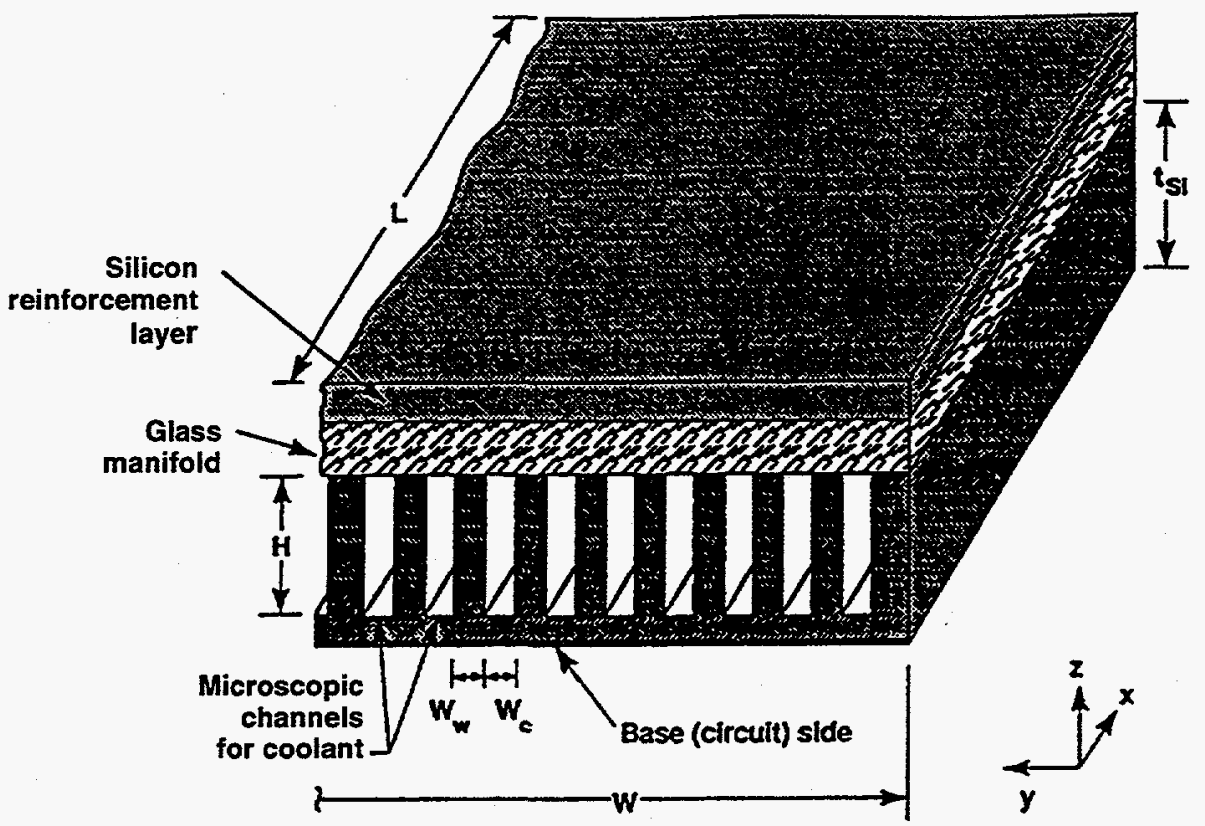

Fig. 7.6. Schematic configuration of a semiconductor heat sink employing microchannel cooling. Typical fin and channel widths are $50 \mu \mathrm{m}$.

Table 7.2. Demonstrated Capability of Microchannel Cooling

\begin{tabular}{|c|c|c|c|c|c|c|c|c|}
\hline Agency & Material & $\begin{array}{c}\text { Channel } \\
\text { Width } \\
(\mu \mathrm{m})\end{array}$ & $\begin{array}{c}\text { Channel } \\
\text { Height } \\
(\mu \mathrm{m}) \\
\end{array}$ & $\begin{array}{c}\text { Channel } \\
\text { Length } \\
(\mu \mathrm{m})\end{array}$ & $\begin{array}{c}\text { Flow Rate/ } \\
\text { Channel } \\
(\mathrm{g} / \mathrm{s})\end{array}$ & $\begin{array}{c}\text { Pressure } \\
\text { Drop } \\
\text { (psi) }\end{array}$ & $\begin{array}{c}\text { Heat Flux } \\
\left(\mathrm{W} / \mathrm{cm}^{2}\right)\end{array}$ & $\begin{array}{c}\text { Local } \\
\text { Thermal } \\
\text { Resistance } \\
\left(\mathrm{C}-\mathrm{cm}^{2} / \mathrm{W}\right)\end{array}$ \\
\hline \multirow[t]{5}{*}{ LLNL } & $\mathrm{Si}$ & 50 & 302 & 14000 & 0.043 & 31 & 790 & 0.090 \\
\hline & $\mathrm{Si}$ & 55 & 400 & 14000 & 0.085 & 53 & 1309 & 0.083 \\
\hline & $\mathrm{Si}$ & 25 & 150 & 1400 & 0.014 & 50 & 2700 & 0.014 \\
\hline & $\mathrm{Si}$ & 25 & 200 & 1850 & 0.0175 & 55 & 1860 & 0.014 \\
\hline & $\mathrm{Si}$ & 50 & 200 & 4000 & 0.155 & 50 & 111 & 0.094 \\
\hline \multirow[t]{3}{*}{ MIT } & InP & 160 & 160 & 9525 & 0.018 & 25 & 68 & 0.100 \\
\hline & InP & 220 & 165 & 9700 & 0.033 & 50 & 114 & 0.072 \\
\hline & $\mathrm{Si}$ & 100 & 400 & 10000 & 0.5 & 70 & 500 & 0.040 \\
\hline Cornell & $\mathrm{Si}$ & 40 & 400 & 3200 & 0.027 & 50 & 100 & 0.05 \\
\hline Saddleback & $\mathrm{Cu}$ & 25 & 225 & 600 & 0.012 & 45 & 90 & 0.083 \\
\hline Perkins-Elmer & $\mathrm{Si}$ & 36 & 420 & 10000 & 0.013 & 45 & 600 & 0.009 \\
\hline \multirow[t]{2}{*}{ NC State } & $\mathrm{Cu}$ & 5870 & 1000 & 100000 & 31.5 & 16 & 42 & 0.33 \\
\hline & $\mathrm{Cu}$ & 5870 & 100 & 100000 & 3.15 & 41 & 42 & 0.40 \\
\hline Nipon T\&T & $\mathrm{Al} 203$ & 800 & 400 & 86000 & 0.46 & $?$ & 24 & 8.0 \\
\hline \multirow[t]{2}{*}{ McDonnell Douglas } & $\mathrm{Cu}$ & $?$ & $?$ & 10000 & $5.6 / \mathrm{cm}^{2}$ & 80 & 125 & 0.125 \\
\hline & $\mathrm{BeO}$ & $?$ & $?$ & 10000 & $5.6 / \mathrm{cm}^{2}$ & 20 & 125 & 0.26 \\
\hline
\end{tabular}

Figure 7.7 presents calculated aperture blockage versus the maximum capability for surface heat flux for a $0.3-\mathrm{cm}$-thick silicon window using water as a coolant. 


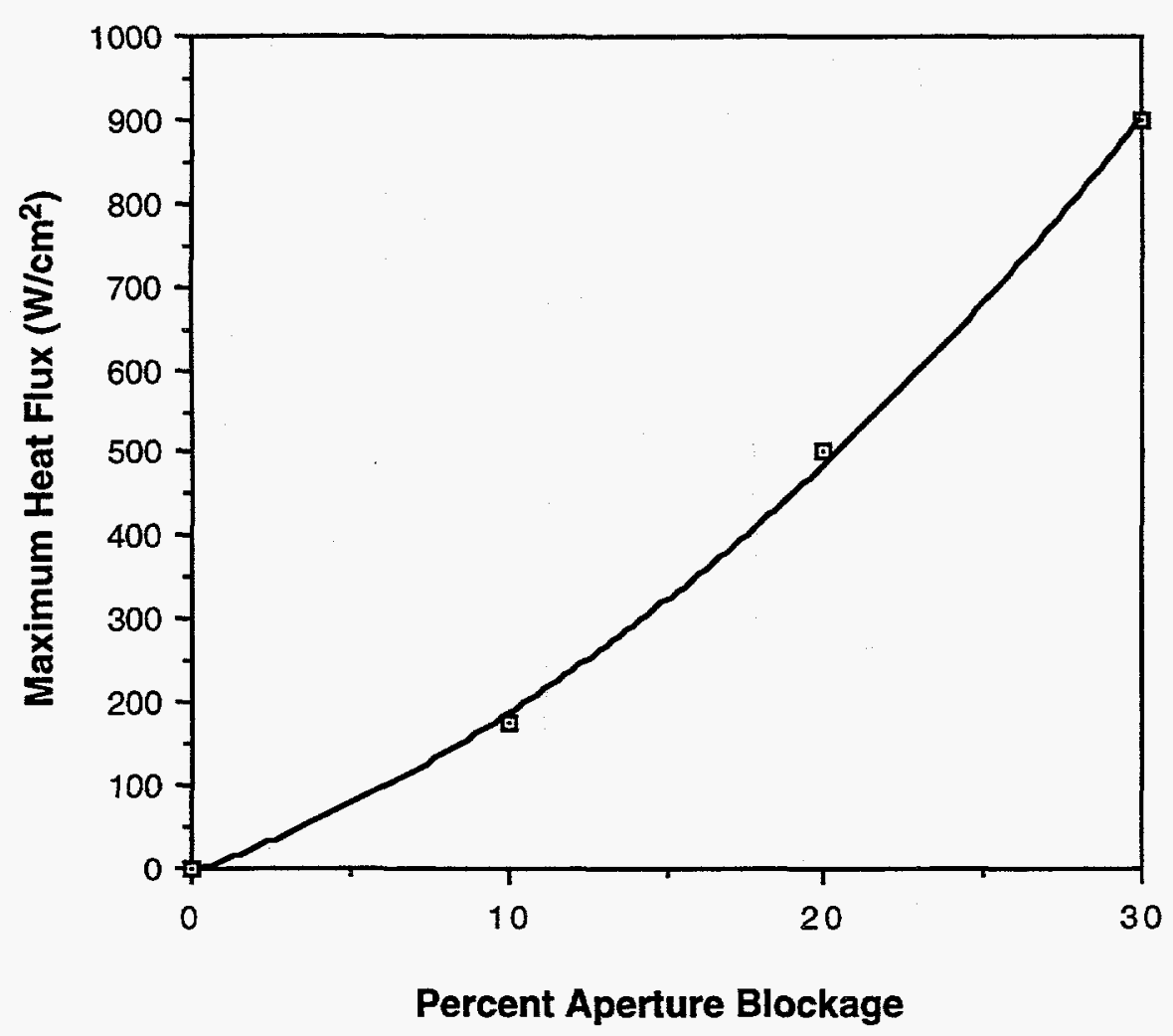

Fig. 7.7. Aperture blockage versus surface heat flux for a typical microchannel-cooled IR window.

\section{Example Calculation}

An example of a microchannel cooling design follows for a $10 \mathrm{~cm}$ quartz window exposed to a surface flux of $40 \mathrm{~W} / \mathrm{cm}^{2}$.

The total heat load on the window is

$$
(\pi / 4)\left(D^{2}\right)(q / A)=(\pi / 4)(100)(40)=3.14 \mathrm{~kW},
$$

where

$\mathrm{D}=$ window aperture $(\mathrm{cm})$,

$(\mathrm{q} / \mathrm{A})=$ surface thermal flux $\left(\mathrm{W} / \mathrm{cm}^{2}\right)$.

Assuming an allowable rise of $50^{\circ} \mathrm{C}$ in the cooling water temperature, the required total window coolant flow is

$$
\mathrm{m}=\mathrm{q} / \mathrm{c}_{\mathrm{p}} \Delta \mathrm{T}=3140 / 4.21(50)=14.9 \mathrm{~g} / \mathrm{s},
$$


where

$$
\begin{aligned}
\mathrm{m} & =\text { mass flow rate }(\mathrm{g} / \mathrm{s}) \\
\mathrm{q} & =\text { total thermal load on window }(\mathrm{W}), \\
\mathrm{c}_{\mathrm{p}} & =\text { specific heat of coolant (water) }\left(\mathrm{J} / \mathrm{g}{ }^{\circ} \mathrm{C}\right), \\
\Delta \mathrm{T} & =\text { temperature rise of coolant }\left({ }^{\circ} \mathrm{C}\right) .
\end{aligned}
$$

If the window contains ( $\mathrm{n}$ ) uniformly spaced flow channels of hydraulic diameter (d), the required coolant flow rate per channel is

$$
m_{n}=m / n(g / s)
$$

For a given pressure difference, the flow per channel is given by the HagenPoiseuille relation:

$$
m_{n}=\left(\rho \pi d^{4} / 128 \mu\right)(\Delta P / \Delta x)
$$

where

$$
\begin{aligned}
& \mathrm{m}_{\mathrm{n}}=\text { flow rate per channel }(\mathrm{g} / \mathrm{s}) \\
& \mathrm{d}=\text { hydraulic diameter of channel }(\mathrm{cm}) \\
& \mathrm{\rho}=\text { coolant density }\left(\mathrm{g} / \mathrm{cm}^{3}\right) \\
& \mu=\text { coolant viscosity }(\text { poise }) \\
& \Delta \mathrm{P}=\text { coolant pressure drop }\left(\mathrm{d} / \mathrm{cm}^{2}\right) \\
& \Delta \mathrm{x}=\text { window aperture }(\mathrm{cm})
\end{aligned}
$$

Assuming a coolant supply pressure of $68.9 \mathrm{~N} / \mathrm{cm}^{2}(100 \mathrm{psi})$ and a flow channel separation of $0.1 \mathrm{~cm}$, for a total of 100 channels across the window aperture, the required microchannel diameter is given by

$$
\mathrm{d}^{4}=\mathrm{m}_{\mathrm{n}}(128) \mu \Delta \mathrm{x} / \rho \pi \Delta \mathrm{P}=0.149(128)(0.0062)(10) / 0.99(3.14)(68.9)
$$

or

$$
\mathrm{d}=0.015 \mathrm{~cm}
$$

The percent blockage of the aperture with this microchannel diameter will be $15 \%$. The percent blockage may be reduced by decreasing the number of channels and increasing the channel dimensions. Figure 7.8 provides a plot of the window blockage as a function of the number of microchannels for the $10-\mathrm{cm}$ quartz window aperture and heat load considered. 


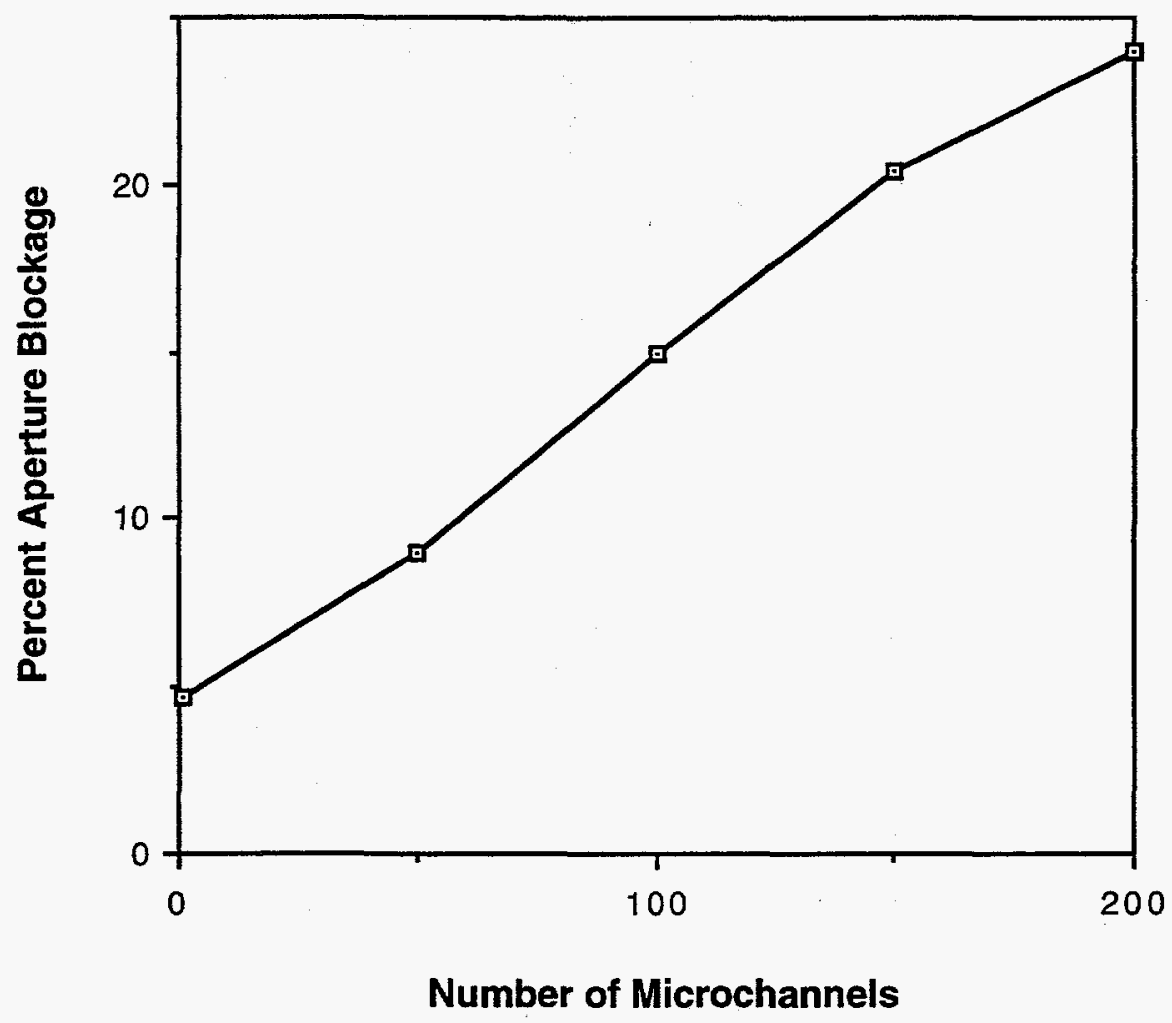

Fig. 7.8. Effect of the number of microchannels on the percentage of window blockage.

For a microchannel depth of $0.025 \mathrm{~cm}$ and the assumptions used in the example, $q^{\prime}=4 \mathrm{~W}$ and $\left(T_{1}-T_{s}\right)=104^{\circ} \mathrm{C}$. This is the temperature difference between the microchannel wall and the window surface. The temperature difference from the coolant fluid to the microchannel wall may be calculated from the Colburn equation:

$$
\mathrm{Nu}=0.023 \operatorname{Re}^{0.8} \operatorname{Pr}^{0.33},
$$

where

$\mathrm{Nu}=$ Nusselt number $=\mathrm{h} \mathrm{d} / \mathrm{k}$,

$\mathrm{h}=$ wall to fluid heat transfer coefficient $\left(\mathrm{W} / \mathrm{m}^{2} \mathrm{~K}\right)$,

$\operatorname{Re}=$ Reynold's number $=\mathrm{Vd} \rho / \mu$.

The window temperature distribution may be estimated by considering the channels as buried sinks in a semi-infinite plane as indicated schematically in Fig. 7.9. The resulting temperature and heat flux distribution is given by the following (Ref. 37):

$$
\mathrm{q}^{\prime} / \mathrm{k}\left(\mathrm{T}_{1}-\mathrm{T}_{\mathrm{s}}\right)=2 \pi / \ln ((2 \mathrm{~L} / \pi \mathrm{d}) \sinh (2 \pi \mathrm{t} / \mathrm{L})),
$$




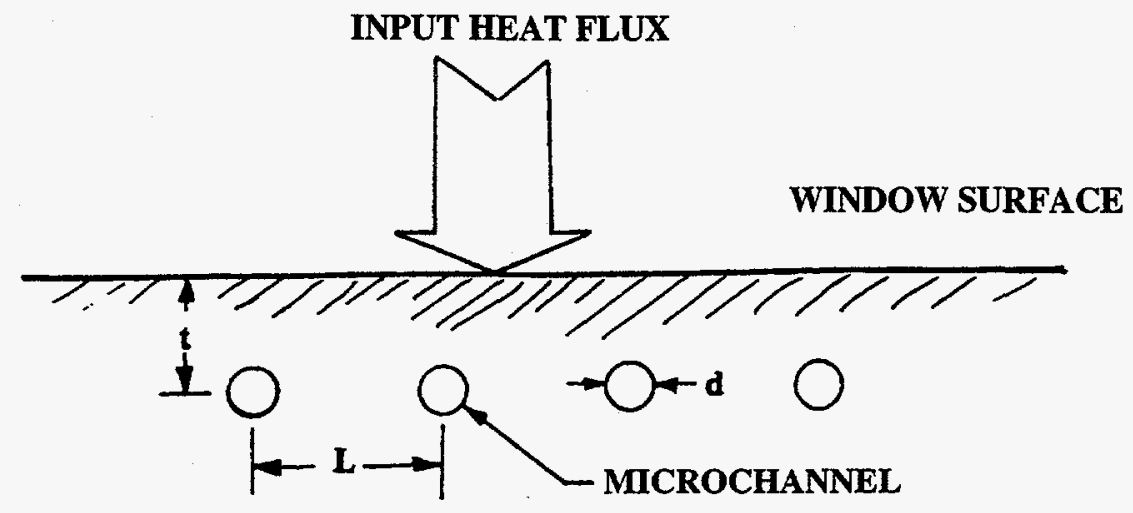

Fig. 7.9. Nomenclature for microchannel analysis.

where

$\mathrm{q}^{\prime}=$ heat flow per unit length of microchannel (W),

$\mathrm{k}=$ thermal conductivity of window material (W/cm K),

$\mathrm{L}=$ microchannel spacing $(\mathrm{cm})$,

$t=$ depth of microchannel from heated surface $(\mathrm{cm})$,

$\mathrm{T}_{1}=$ channel surface temperature,

$\mathrm{T}_{\mathrm{s}}=$ window surface temperature.

In the application of this correlation, it is assumed that the flow is developed and turbulent. The first of these assumptions is conservative in that the heattransfer coefficients in the developing flow region would be higher. The validity of the assumption of turbulent flow will depend on the magnitude of the Reynold's number with turbulent correlations applying at Reynold's numbers as low as 1000 for microchannel flows where the wall roughness is comparatively large in terms of the channel dimensions.

In our example,

$$
\operatorname{Re}=V \mathrm{~d} \rho / \mu=4(0.149) / \pi(0.015)(0.0062)=2054,
$$

and the assumption of turbulent flow appears valid. The Prandtl number for water at $42.5^{\circ} \mathrm{C}$ is 4.1 , and the resultant Nusselt number is

$$
\mathrm{Nu}=0.023(2054)^{0.8}(4.1)^{0.33}=16.3,
$$

and the corresponding heat-transfer coefficient is

$$
h=N u(k) / d=16,3(0.0062) / 0.15=6840 \mathrm{~W} / \mathrm{m}^{2} \mathrm{~K} .
$$

The maximum window surface temperature may be given in terms of the coolant inlet temperature (assumed to be $35^{\circ} \mathrm{C}$ for properties):

$$
\mathrm{T}_{\text {max }}=\mathrm{T}_{\text {inlet }}+\Delta \mathrm{T}_{\text {fluid }}+\mathrm{q}^{\prime} / \mathrm{h} \mathrm{A}_{\mathrm{c}}+\left(\mathrm{T}_{1}-\mathrm{T}_{\mathrm{s}}\right)
$$


where

$\mathrm{T}_{\max }=$ maximum window surface temperature,

$\mathrm{T}_{\text {inlet }}=$ fluid inlet temperature,

$\Delta \mathrm{T}_{\text {fluid }}=$ allowable coolant temperature rise,

$\mathrm{q}^{\prime} \quad=$ heat input per unit length of flow channel $=4 \mathrm{~W}$,

$\mathrm{h} \quad=$ heat-transfer coefficient,

$A_{c} \quad=$ flow channel surface area per unit length,

$\mathrm{T}_{1}=$ channel surface temperature,

$\mathrm{T}_{\mathrm{s}} \quad=$ window surface temperature.

In the example, then

$$
\mathrm{T}_{\max }=35+50+12.4+104=197.4^{\circ} \mathrm{C}
$$

As the temperature rise from the microchannel wall to the window surface dominates, the window temperature could be reduced most easily by decreasing the microchannel diameter and increasing the number of channels. An alternative is to reduce the depth of the microchannels from the heated surface. The effect of this change in the example case is indicated in Fig. 7.10.

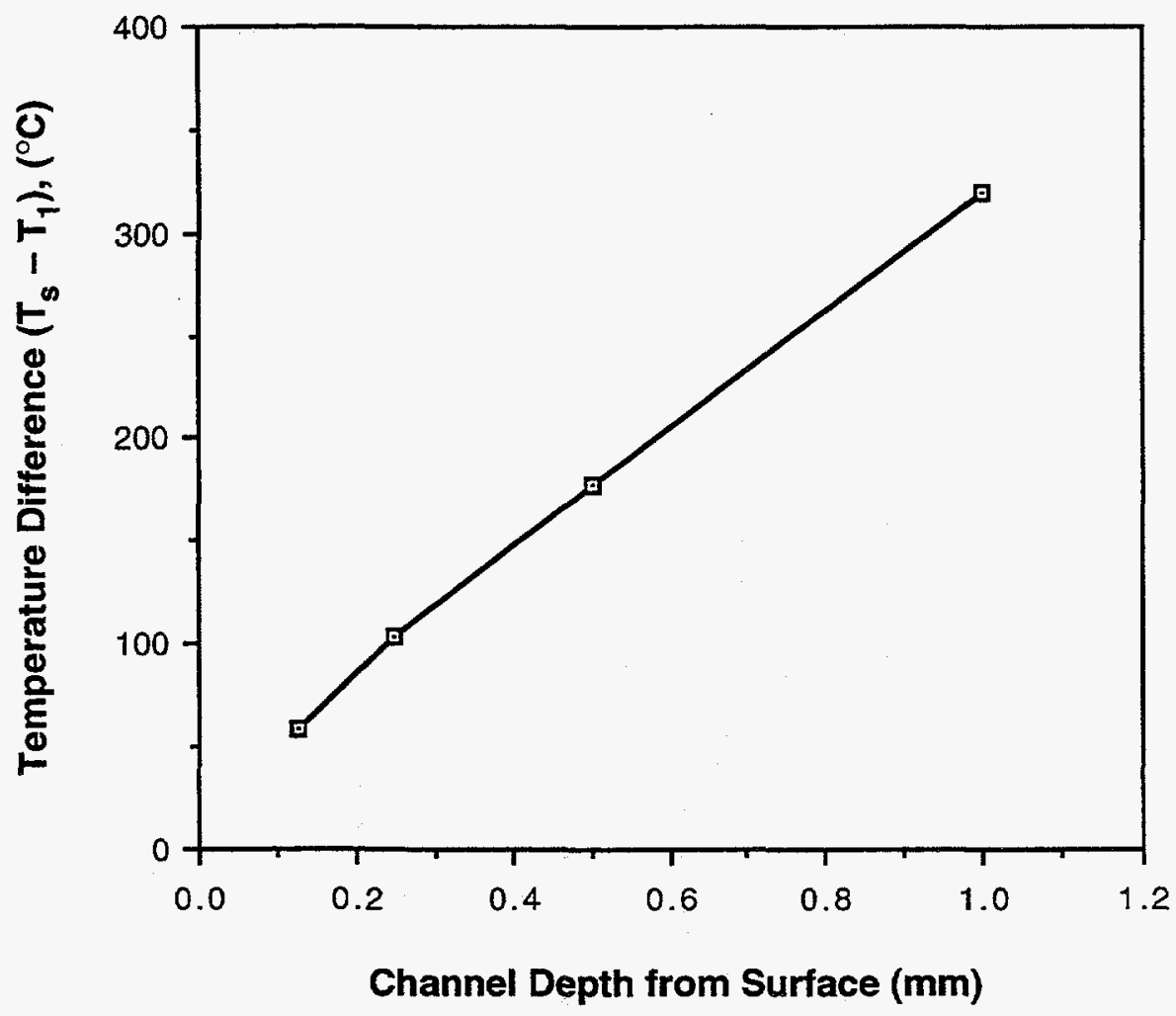

Fig. 7.10. Effect of microchannel depth on temperature difference. 
The percentage of blockage may be reduced by changing the aspect ratio of the flow channels, which, in this example, have been assumed to be circular. If the hydraulic radius of the flow channel is maintained constant while the aspect ratio is changed to reduce the width of the channel, the aperture blockage will be reduced. The effect of the change in aspect ratio on blockage is indicated in Fig. 7.11.

For the diagnostic-sensor window applications, the flow channel dimensions and spacing would be optimized for maximum sensor signal transmission within the allowable temperature and stress limits of the window material (Ref. 38). Implementation problems would include the routing of fluid lines at the higher pressures required in this type of system. Estimated window blockage would be in the 0.1 range and should be achievable with quartz, and lower values should be achievable with the higherconductivity window materials. The effect of window material conductivity on the temperature difference between the microchannel surface and the window surface is shown in Fig. 7.12.

Figure 7.13 is a conceptual drawing of a window that is cooled internally by using microchannels of the type discussed in this section.

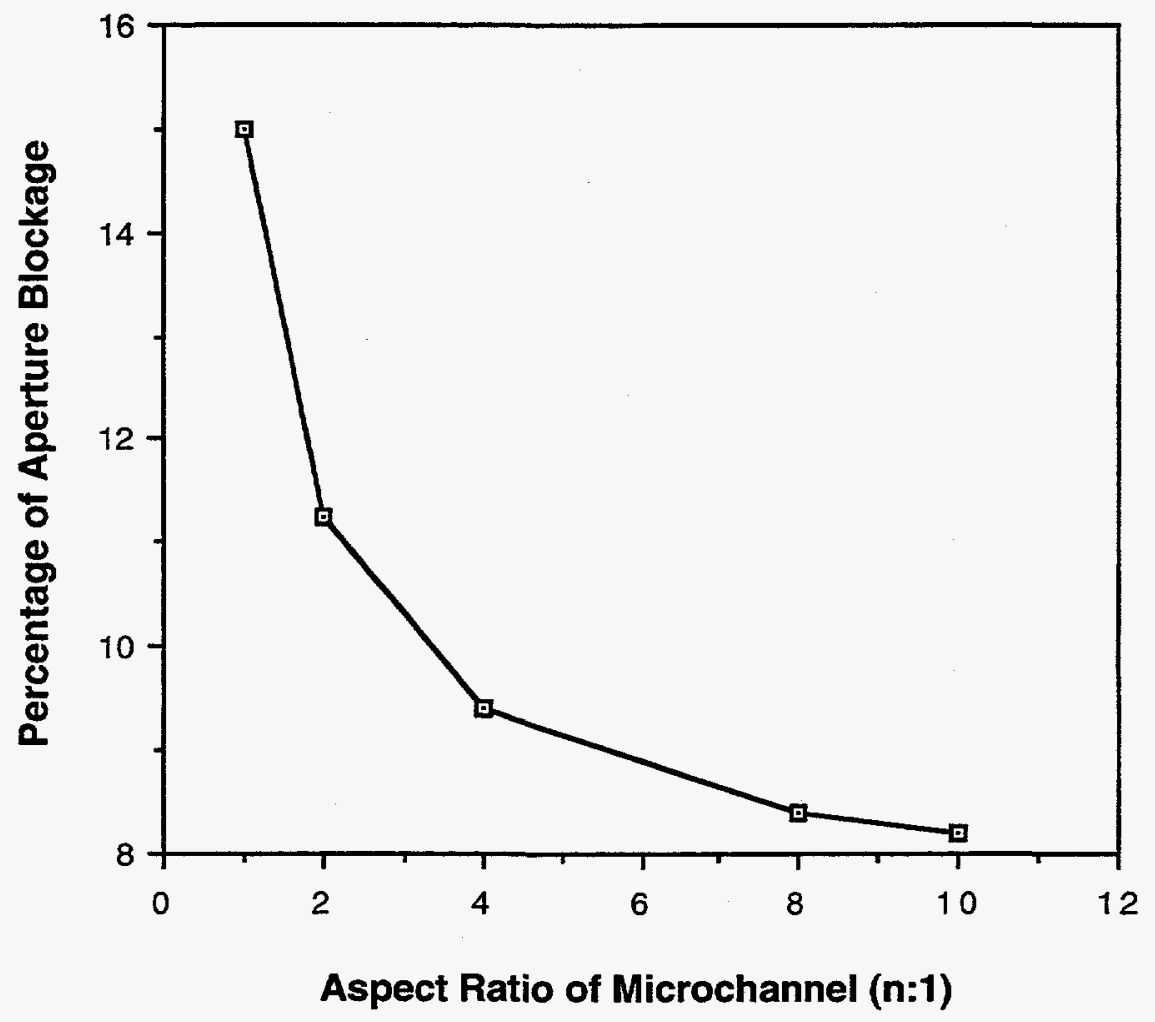

Fig. 7.11. Effect of microchannel aspect ratio on percent aperture blockage. 


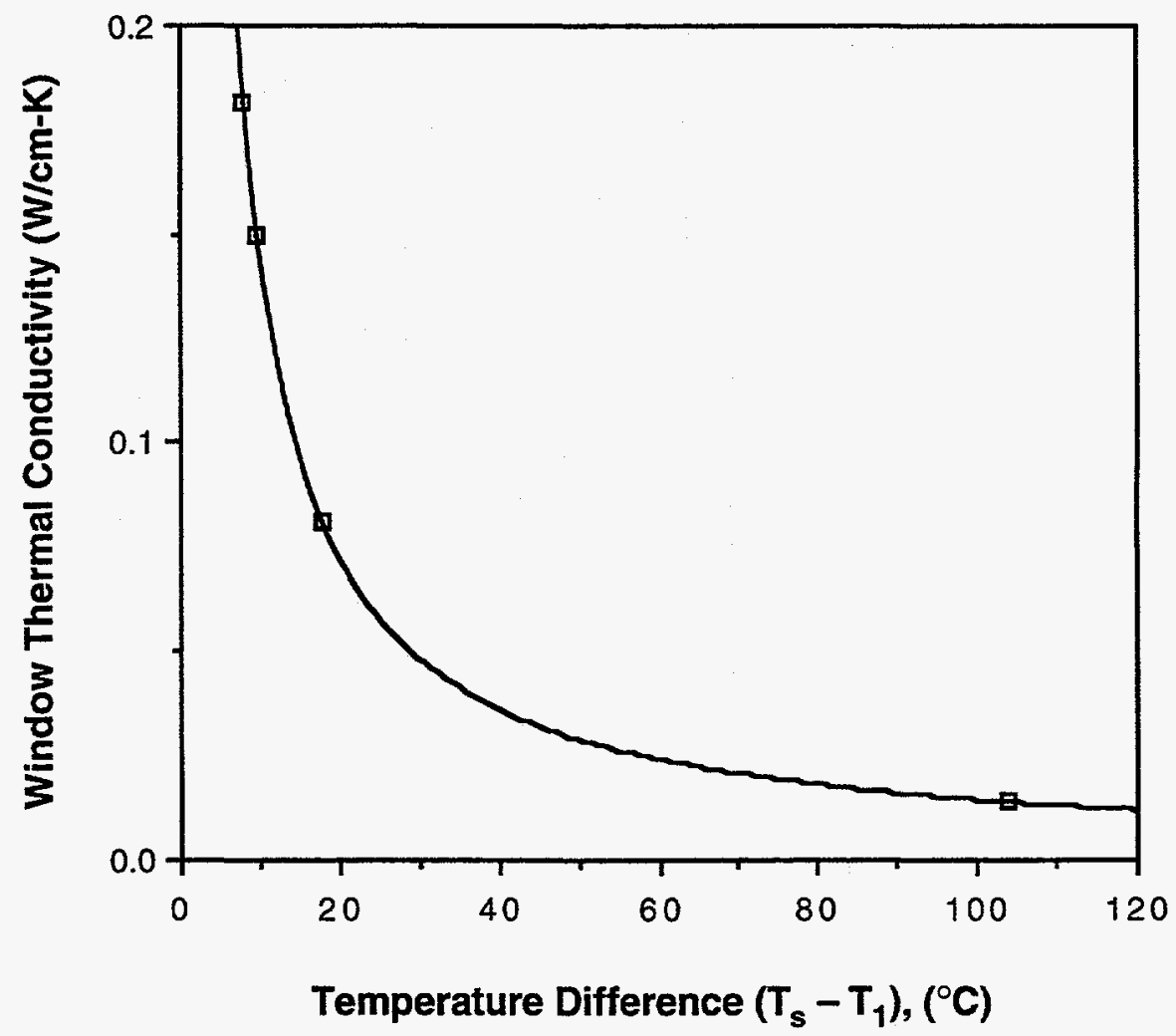

Fig. 7.12. Effect of window conductivity on the temperature difference between the microchannel surface and the window surface.

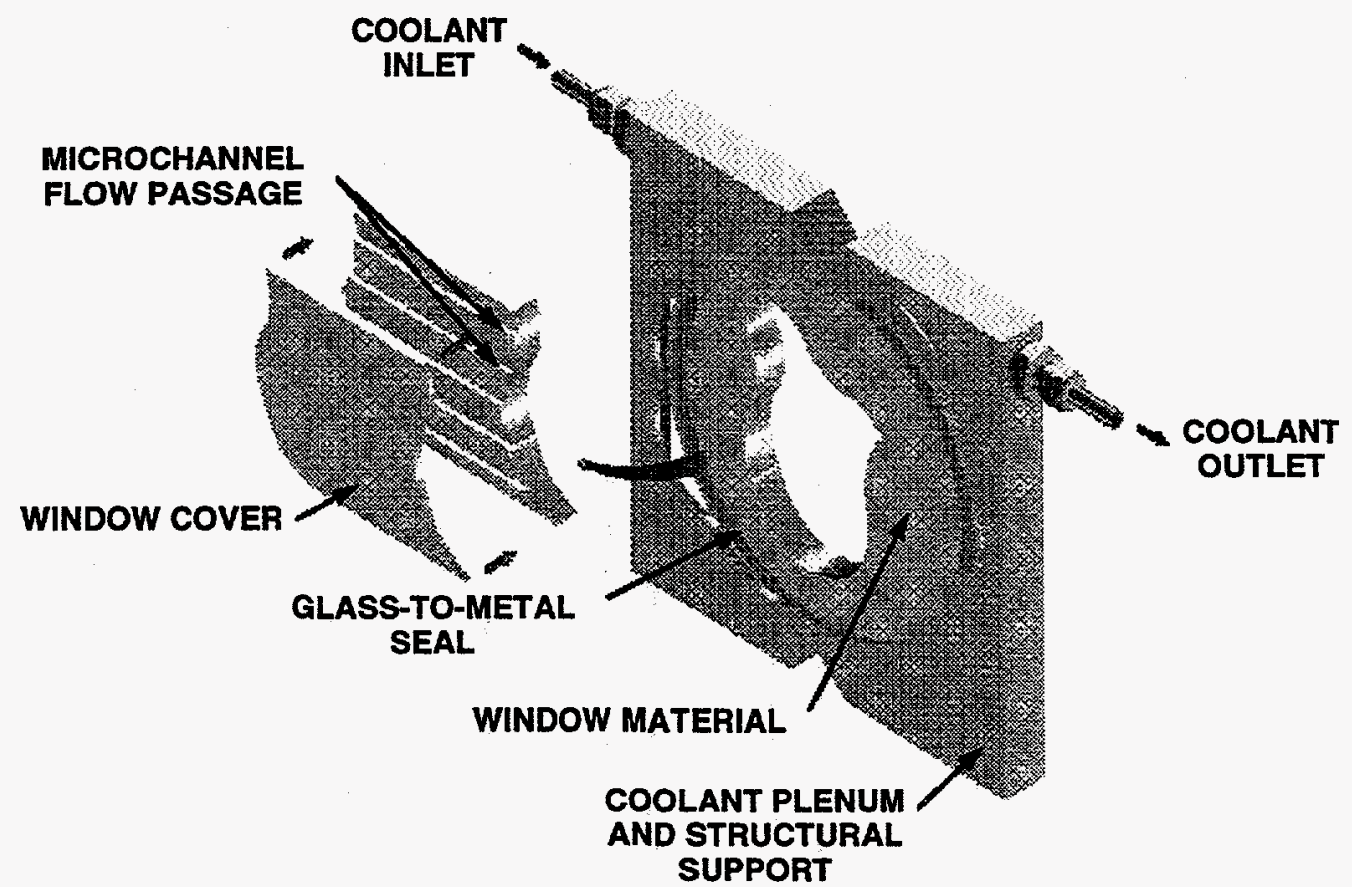

Fig. 7.13. Schematic of an internally cooled window using microchannels. 
A baseline design for a microchannel-cooled window has been done for each of the window materials considered. The resulting microchannel flow parameters, dimensions, and temperatures are summarized in Table 7.3. The corresponding blockage percentage varies from $15 \%$ for the quartz case, as discussed above, to less than $5 \%$ for the $\mathrm{ZnSe}$ and $\mathrm{MgF}_{2}$ cases. $\mathrm{CaF}_{2}$ is intermediate at $7.5 \%$ blockage. All of these blockage factors are calculated at unity microchannel aspect ratio and could be reduced significantly by changing the microchannel aspect ratio while maintaining a constant hydraulic diameter.

In Table 7.3

$\mathrm{n}$ = number of microchannels across a $10-\mathrm{cm}$ window,

$\mathrm{m}_{\mathrm{n}}=$ mass flow rate of coolant per microchannel,

$\mathrm{d}=$ microchannel diameter (assumed aspect ratio $=1$ ),

$L$ = spacing between microchannels,

$t \quad=$ depth of microchannel below surface of window,

$\operatorname{Re}=$ Reynold's number of flow,

$\mathrm{Nu}=$ Nusselt number,

$\mathrm{h}=$ heat-transfer coefficient between fluid and wall,

$\Delta \mathrm{T}_{\mathrm{f}}=$ delta $\mathrm{T}$ from fluid to wall,

$\Delta \mathrm{T}_{\mathrm{s}}=$ delta $\mathrm{T}$ from wall to window surface,

$\Delta \mathrm{T}_{\mathrm{t}}=$ total delta $\mathrm{T}$ from coolant inlet to surface hot spot,

and the assumptions for all cases are the following: input thermal flux is $40 \mathrm{~W} / \mathrm{cm}^{2}$; window diameter is $10 \mathrm{~cm}$; allowable coolant $\Delta \mathrm{T}$ is $50^{\circ} \mathrm{C}$; and the coolant supply pressure is $68.9 \mathrm{~N} / \mathrm{cm}^{2}$ (100 psi).

\subsection{Periodic Shielding of the Window Aperture}

It would be possible to shield the windows mechanically with a rotating shutter that would attenuate the incident radiation to levels compatible with window edge cooling. This shielding could be accomplished at comparatively high frequency in order to minimize interference with the diagnostic-sensor performance. The shield would consist of a slotted metal disk (cooled). It would, however, require the operation of rotating

Table 7.3. Baseline Characteristics for Microchannel-Cooled Windows

\begin{tabular}{|c|c|c|c|c|c|c|c|c|c|c|c|c|}
\hline Material & $\mathbf{n}$ & $\begin{array}{c}m_{n} \\
(g / s)\end{array}$ & $\begin{array}{c}\text { d } \\
(\mathrm{cm})\end{array}$ & $\begin{array}{c}\mathbf{L} \\
(\mathrm{cm})\end{array}$ & $\begin{array}{c}\mathbf{t} \\
(\mathbf{c m})\end{array}$ & $\mathbf{R e}$ & $\mathbf{N u}$ & $\begin{array}{l}\text { h W/ } \\
\text { cm-K }\end{array}$ & $\begin{array}{l}\Delta \mathbf{T}_{\mathbf{f}} \\
(\mathbf{K})\end{array}$ & $\begin{array}{l}\Delta \mathbf{T}_{\mathbf{s}} \\
(\mathbf{K})\end{array}$ & $\begin{array}{l}\Delta \mathbf{T}_{\mathbf{t}} \\
(\mathbf{K})\end{array}$ & $\begin{array}{c}\text { Blockage } \\
(\%)\end{array}$ \\
\hline Quartz & 100 & 0.149 & 0.015 & 0.1 & 0.025 & 2054 & 16 & 6.84 & 12.4 & 104 & 166.4 & 15 \\
\hline $\mathrm{ZnSe}$ & 20 & 0.75 & 0.022 & 0.5 & 0.125 & 6633 & 41 & 11.7 & 24.8 & 60.8 & 135.6 & 5.1 \\
\hline $\mathrm{CaF}_{2}$ & 40 & 0.37 & 0.019 & 0.25 & 0.063 & 3996 & 27 & 8.9 & 18.9 & 58.2 & 127.1 & 7.5 \\
\hline $\mathrm{MgF}_{2}$ & 20 & 0.75 & 0.022 & 0.5 & 0.125 & 6633 & 41 & 11.7 & 24.8 & 73.9 & 148.6 & 4.4 \\
\hline
\end{tabular}


devices within the high-vacuum environment and would require some periodic maintenance. The need for cooling the shield with the consequent need for rotating seals in the coolant system would probably disqualify this approach. An alternative to cooling the shield would be to allow the shield front (plasma facing) surface to run at radiation equilibrium temperatures (1400-1500 K) with the rear surface insulated internally to provide low exposure temperatures for the windows.

\subsection{Use of Transparent Radiation Shields}

The use of a transparent radiation shield placed between the window and the plasma and operating at radiation equilibrium temperature has been considered. Assuming an absorbtivity/emissivity of 1.0, the shield temperature at an incident plasma flux of $40 \mathrm{~W} / \mathrm{cm}^{2}$ would be about $1900 \mathrm{~K}$. The thermal radiation (black body) from the window facing surface of the shield would be peaked at about $1.8-\mu \mathrm{m}$ wavelengths, with the approximately $40 \%$ of the reradiated energy at wavelengths greater than $3 \mu \mathrm{m}$ absorbed in a quartz window. For a $15-\mathrm{cm}$-diam window the resulting window edge-to-center temperature rise would be $7880^{\circ} \mathrm{C}$. For low-conductivity materials without significant long-wave IR transmittance, this technique would be limited to windows $1-2 \mathrm{~cm}$ in diameter. If materials with good long-wave IR transmittance were used, the absorbed energy would be less; however, the high long-wave IR signal from the shield would limit the use of diagnostic sensors at these wavelengths. Because the range of window diameters for which this technique might be used is essentially the same as that for the edge-cooling technique, it would seem to be of little interest.

An alternative has been suggested in which the transparent radiation shield would be larger in diameter than the shielded window and would itself be cooled by radiation to a cold surface. The shield would rotate to maintain uniform temperature. Edmonds (Appendix B) provides estimated temperatures of the shield, assuming an aperture equal to the shield radius, radiation to a sink at $25^{\circ} \mathrm{C}$, and various emissivities. For $\mathrm{e}=1.0$, a quartz shield would reach approximately $700^{\circ} \mathrm{C}$. Given that this approach requires space, rotating hardware, and coolant lines within the vacuum envelope, other alternatives appear preferable.

\section{CONCLUSIONS AND RECOMMENDATIONS}

Table 8.1 is a summary of the TPX window-cooling methods considered in this report. The general conclusion is that some means of window cooling other than simple heat sinking of the edge of the window to the surrounding structure will be required for all but the smallest windows. Of the cooling or shielding methods considered, the most promising candidates for further investigation for larger windows with diameters to $20 \mathrm{~cm}$ are internal forced-convection microchannel cooling and micro-heat-pipe cooling for windows with diameters of $2-5 \mathrm{~cm}$. Both of these methods have been investigated in depth for other applications and have been implemented in ceramic materials. Demonstrated power-handling capability is in excess of the TPX requirements. Issues to be addressed in their application will include the development of fabrication and sealing 
Table 8.1. Comparison of Potential TPX Window-Cooling Methods

\begin{tabular}{|c|c|c|c|}
\hline Method & Advantages & Issues & Comments \\
\hline $\begin{array}{l}\text { Micro-heat pipes } \\
\text { embedded in window } \\
\text { with heat sinking to } \\
\text { coolant at edge }\end{array}$ & $\begin{array}{l}\text { Phase change system- } \\
\text { provides high degree of } \\
\text { isothermalization. } \\
\text { Passive system-very } \\
\text { reliable and requires no } \\
\text { additional pumps }\end{array}$ & $\begin{array}{l}\text { Some aperture } \\
\text { blockage by heat pipes. } \\
\text { Heat pipe length-to- } \\
\text { diameter ratio limited to } \\
\text { about } 400-500^{\circ} \mathrm{C}\end{array}$ & $\begin{array}{l}\text { Useful candidate for } \\
\text { windows ranging from } \\
4 \text { to } 8 \mathrm{~cm} \text { in diameter. } \\
\text { Working fluids include } \\
\text { ammonia and water }\end{array}$ \\
\hline $\begin{array}{l}\text { Conduction heat sinking } \\
\text { of window to cooled } \\
\text { structure at edge }\end{array}$ & Mechanically simple & $\begin{array}{l}\text { Low conductivity of } \\
\text { window materials limits } \\
\text { window diameter to } \\
<2 \mathrm{~cm}\end{array}$ & $\begin{array}{l}\text { Use for small windows } \\
\text { in better conductivity } \\
\text { materials }\end{array}$ \\
\hline $\begin{array}{l}\text { Shielding of window } \\
\text { by reentrant metal mirrors }\end{array}$ & $\begin{array}{l}\text { Mirror cooling } \\
\text { capability demonstrated } \\
\text { to }>100 \mathrm{~W} / \mathrm{cm}^{2} \text { in laser } \\
\text { applications. } \\
\text { Technique usable with } \\
\text { all window materials }\end{array}$ & $\begin{array}{l}\text { Coolant fluid connec- } \\
\text { tions in vacuum space } \\
\text { Space requirements for } \\
\text { mirrors in enclosure. } \\
\text { Cleaning of mirrors } \\
\text { within vacuum space }\end{array}$ & $\begin{array}{l}\text { Use where other } \\
\text { requirements for mirrors } \\
\text { exist (e.g., field-of-view } \\
\text { [FOV] requirements) }\end{array}$ \\
\hline $\begin{array}{l}\text { Internal forced- } \\
\text { convection cooling of } \\
\text { window by micro- } \\
\text { channels (single phase) }\end{array}$ & $\begin{array}{l}\text { Demonstrated } \\
\text { technology capable of } \\
\mathrm{R}=0.1^{\circ} \mathrm{C}-\mathrm{cm}^{2} / \mathrm{W} \\
\text { Power-handling } \\
\text { capability in excess of } \\
\text { TPX requirements }\end{array}$ & $\begin{array}{l}\text { Some aperture block- } \\
\text { age by flow channels. } \\
\text { Requires fluid connec- } \\
\text { tion to window edge } \\
\text { Supply pressure } 50- \\
100 \text { psi }\end{array}$ & $\begin{array}{l}\text { Usable with water or } \\
\text { ammonia coolants at } \\
\text { system temperatures. } \\
\text { Would enable windows } \\
\text { to }>20 \mathrm{~cm} \text { in any of the } \\
\text { candidate materials. } \\
\text { Recommended for } \\
\text { development }\end{array}$ \\
\hline $\begin{array}{l}\text { Forced-convection } \\
\text { cooling of window back } \\
\text { surface (gas) }\end{array}$ & $\begin{array}{l}\text { No fluid connection to } \\
\text { window. } \\
\text { Coolant system } \\
\text { accessible }\end{array}$ & $\begin{array}{l}\text { Axial conduction limits } \\
\text { window thickness. } \\
\text { Heat-transfer } \\
\text { coefficients limited }\end{array}$ & $\begin{array}{l}\text { Inadequate cooling } \\
\text { capability for TPX } \\
\text { requirements }\end{array}$ \\
\hline $\begin{array}{l}\text { Intermittent mechanical } \\
\text { shielding of window }\end{array}$ & $\begin{array}{l}\text { Mechanically complex, } \\
\text { requires moving structure } \\
\text { in vacuum enclosure. } \\
\text { Shield will probably } \\
\text { require cooling }\end{array}$ & $\begin{array}{l}\text { Mechanical implemen- } \\
\text { tation. } \\
\text { Space allocation within } \\
\text { vacuum enclosure }\end{array}$ & Not recommended \\
\hline $\begin{array}{l}\text { High } \mathrm{K} \text { window coating/ } \\
\text { layering (diamond) } \\
\text { with window edge heat } \\
\text { sinking to structure }\end{array}$ & $\begin{array}{l}\text { Completely passive. } \\
\text { Usable with long- } \\
\text { wavelength IR windows }\end{array}$ & $\begin{array}{l}\text { Technology for diamond } \\
\text { coatings }>1 \mathrm{~mm} \text { thick } \\
\text { in larger diameters } \\
\text { not available }\end{array}$ & $\begin{array}{l}\text { Use as diamond-coating } \\
\text { technology becomes } \\
\text { available }\end{array}$ \\
\hline $\begin{array}{l}\text { Optically transparent } \\
\text { shield at radiation } \\
\text { equilibrium temperature }\end{array}$ & $\begin{array}{l}\text { Passive, no coolant } \\
\text { required }\end{array}$ & $\begin{array}{l}\text { Reradiation from shield } \\
\text { significant for quartz. } \\
\text { Shield runs at high } \\
\text { temperature }\end{array}$ & $\begin{array}{l}\text { May be usable for long- } \\
\text { wavelength IR windows } \\
\text { if interference with } \\
\text { sensors is not a problem }\end{array}$ \\
\hline
\end{tabular}


procedures for the window materials and investigation of optical effects. In lowconductivity materials such as quartz, the microchannel or micro-heat-pipe spacing will have to be approximately $1 \mathrm{~mm}$ with flow passage widths of about $50 \mu \mathrm{m}$. Although the percentage blockage of the aperture is expected to be about $5 \%$, the blockage will consist of an array of fine lines across the window, and the effect of this grid on the sensor operation must be considered, particularly for off-axis viewing. Recommendations are that a cooled-window development program addressing these issues be initiated to ensure performance of the diagnostic windows in the TPX system.

\section{RECOMMENDED WINDOW DEVELOPMENT PROGRAM}

We recommend a window development program based on the problems and solutions we have identified in this report. In order to develop and demonstrate a window designed to operate with visible and IR sensors, while subject to heat fluxes up to $40 \mathrm{~W} / \mathrm{cm}^{2}$ from short-wavelength radiation, some specific research and development actions are necessary. It is anticipated that other planned tokamak systems such as the International Thermonuclear Experimental Reactor (ITER) will be subject to the same diagnostic window problems and would benefit from the same development program. Therefore, it is recommended that the developmental program reflect the requirements of these other systems in terms of diagnostic window exposure levels. This program may be accomplished within the task outlines and levels of effort outlined in the key elements below:

- Refinement of the window incident radiation spectrum by using the MIST code and anticipated plasma characteristics and contaminant levels.

- Update of window requirements in terms of aperture, material, sensor wavelength, and field of view for TPX and ITER.

- Selection of the design cooling method, materials, and geometry for hardware development and demonstration. This selection is anticipated to be the internal forced-convection, microchannel-cooling method discussed above. However, alternatives, particularly the micro-heat-pipe approach, will be considered in the choice of the final design.

- Design development and optimization for the experimental window demonstration. Development of a finite-element window model would incorporate realistic boundary conditions, internal or external flow interfaces, local heat sources, and heattransfer coefficients. The anticipated incident radiation spectrum for the TPX and ITER windows, together with improved definition of absorption characteristics of the window materials, will be used to determine local window thermal loadings. Coolant channel geometry and location will be varied to determine the effects on window temperatures, stresses, and flow rates. The anticipated outcome of the analysis will be the specification of microchannel flow channel dimensions and spacing in order to minimize the optical effects of the window-cooling system while maintaining stresses and temperatures within allowable limits under the anticipated environment. 
- Fabrication of test hardware implementing the selected window-cooling method. Fabrication of the experimental demonstration window design tentatively will be based on a circular quartz window having a diameter of $10-15 \mathrm{~cm}$ and a thicknessto-diameter ratio of approximately 0.1 . Coolant flow channels will be machined or etched into the surface of the window disk and sealed with a cover layer of optically transparent material. Coolant fluid headers will be bonded to the window, and flow line attachments will be provided. Cold flow tests will be performed to verify design pressure drop and flow predictions.

- Window thermal performance testing. The assembled test window will be thermally loaded with surface bonded resistance heaters. Cooling performance tests will be conducted with window surface temperatures determined as a function of coolant flow parameters and surface thermal loads to the design maximums. Test instrumentation will include flow calorimetry, window temperatures, and, if possible, surface strain gages.

- Window optical performance testing. The effect of the window-cooling system implementation on optical performance at selected sensor wavelengths will be determined by target visualization through the window over a range of viewing angles.

- Reporting. A report detailing the window design, fabrication, and experimental investigation will be prepared and disseminated. Recommendations for diagnosticsensor window implementation for TPX and ITER will be included in the report. A task schedule for the recommended effort is given in Fig. 9.1. The estimated level of effort for the proposed effort is $\$ 150,000$.

\section{ACKNOWLEDGMENTS}

We would like to acknowledge the guidance of Phil Edmonds from the University of Texas and the previous work of Robert Ellis from the Princeton Plasma Physics Laboratory (PPPL). Our work was supported by the TPX project at PPPL from contract ICO number S-03861-K. The TPX project at PPPL was supported by the US Department of Energy under contract number DE-AC02-76CH03073. 


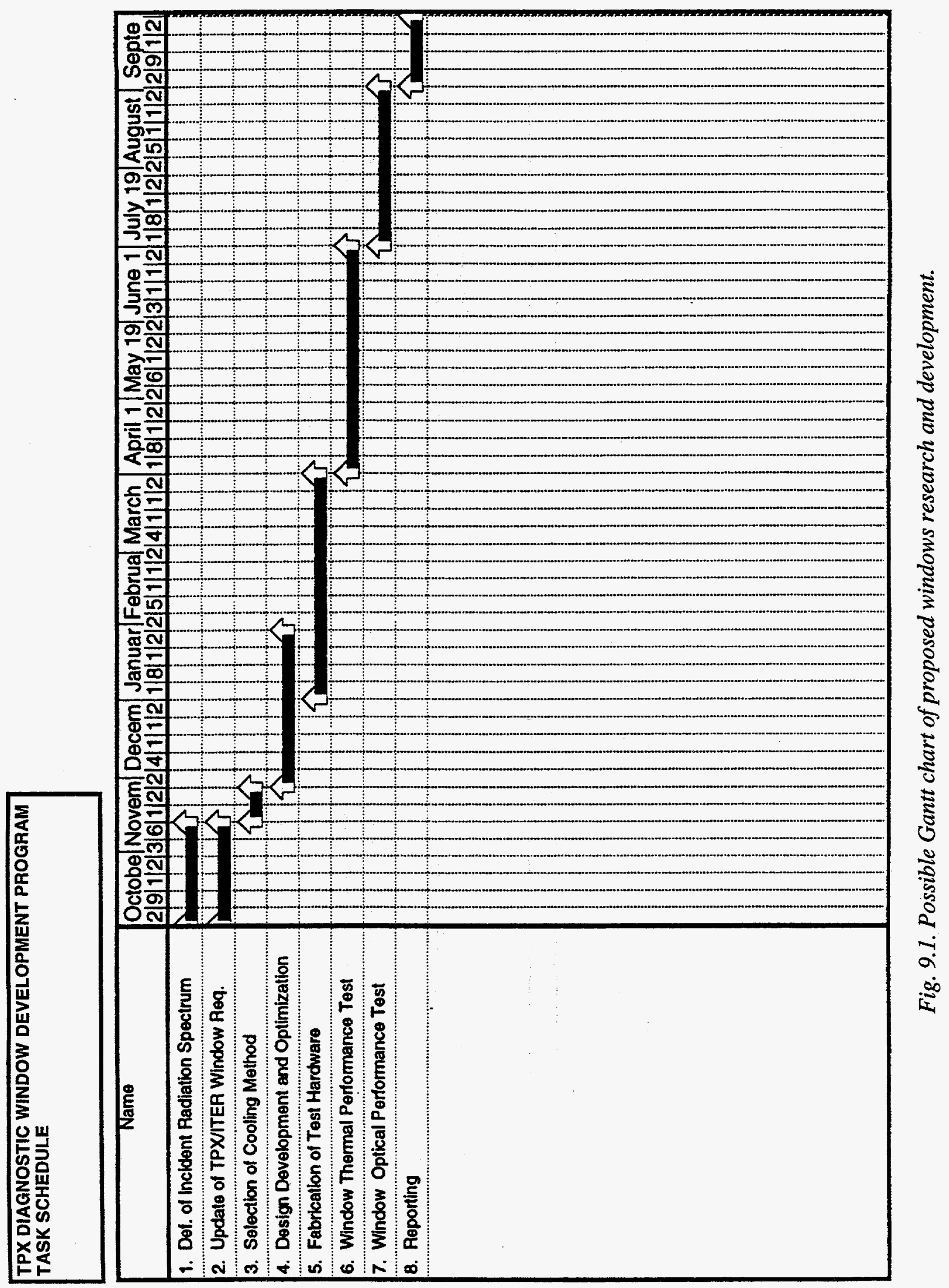




\section{REFERENCES}

1. "TPX Engineering Managers' Meeting," PPPL, 91-950316-PPPL-RSimmons-01, March 1995; "Response to Diagnostics Configuration Review Chits," TPX Diagnostics Configuration Review, 62-031795-UT-PEdmonds-01, October 1994.

2. Isler, R. C., "Impurities in Tokamaks," Nuclear Fusion, Vol. 24, No. 12 (1984).

3. Alan Ramsey, PPPL, Personal Communication, August 1995.

4. Orlinskij, D. V., and Magyar, G., "Plasma Diagnostics on Large Tokamaks," Nuclear Fusion, Vol. 28, No. 4, p. 669 (1988).

5. Feldshteyn, Y., et al., "TPX Vacuum Vessel Heating and Cooling System," 15th IEEE/NPSS Symposium on Fusion Engineering, Vol. 1, 1993.

6. Wolf, W. L., and Zissis, G. J., Eds., The Infrared Handbook, Office of Naval Research, Washington, D.C., 1978.

7. Musikant, S., Optical Materials, B.J. Thompson, Ed., Marcel Dekker.

8. Raznejevic, K., Handbook of Thermodynamic Tables and Charts, McGraw-Hill Book Co., New York, NY, 1976.

9. Kreidl, N. J., and Rood, J. L., "Optical Materials," Chapt. 5, Applied Optics and Optical Engineering, Vol. 1, R. Kingslake, Ed., Academic Press, New York, NY, 1965.

10. Robinson, J. N., "Design of Viewing Windows for Controlled-Atmosphere Chambers," ORNL/TM-6864, March 1980.

11. Roark, R. J., Formulas for Stress and Strain, 4th ed., 1965, McGraw-Hill Book Co.

12. Palmer, J. R. , "Continuous Wave Laser Damage on Optical Materials," Optical Engineering, Vol. 22, No. 4, July 1983.

13. Palmer, J. R., "Thermal Shock: Catasrophic Damage to Transmissive Optical Components in High Power CW and Repetitive Pulsed Laser Environments, pp. 87-140, Mirrors and Windows for High Power/High Energy Laser Systems, Klein, C. A., Ed., SPIE Proceedings, Vol. 1047, January 1989.

14. Afsar, M. N., and Chi, H., "Window Materials for $110 \mathrm{GHz}$ and $280 \mathrm{GHz}$ Gyrotrons," Proceedings of the International Conference on Millimeter and Submillimeter Waves and Their Applications, SPIE Vol. 2211, January 1994.

15. Holderbaum, G. S., and Phillips, R. J., "Spherical Vacuum-Interface Window with Axial-Flow Impingement Cooling," p. 147, SPIE Vol. 1047, Mirrors and Windows for High Power/High Energy Laser Systems, 1989. 
16. Apollonov, V. M., et al., “Application of Ultrasonic Capillary Effect in Elements of Power Optics Cooled by Means of a Heat Pipe," p. 618, NIST 801, Laser Induced Damage in Optical Materials, 1989.

17. HVM Joint Program Office (K. Schoenberg et al.), "Hypervelocity Missile Concept Definition Report," Los Alamos National Laboratory document LA-CP-9422, April 1994.

18. Willett, R., et al., "Experimental Investigation of the Effects of Thermal Gradients on Optical Transmission Through Sapphire Windows," AIAA 93-2669, 2nd Annual AIAA BMDO Interceptor Technology Conference, June 1993.

19. Lumb, S., Majeski, J., and Mills, S., "Window Survivability in Endoatmospheric Environments," AIAA 93-2674, 2nd Annual AIAA BMDO Interceptor Technology Conference, June 1993.

20. Moody, H. L., et al., "Forebody and Sensor Aperture Cooling for Endoatmospheric Interceptors," AIAA 93-2686, 2nd Annual AIAA BMDO Interceptor Technology Conference, June 1993.

21. Wojciechowski, C. J., and Ravi, K. V., "Internally Cooled Window for Endoatmospheric Homing-Update," AIAA-93-2684, 2nd Annual AIAA SDIO Interceptor Technology Conference, June 1993.

22. Burzlaff, B. H., et al., "Active Two-Phase Cooling of an IR Window for a Hypersonic Interceptor," AIAA 93-2685, 2nd Annual AIAA BMDO Interceptor Technology Conference, June 1993.

23. Yuen, W. W., Fleishman, R. V., "Parametric Study of Mesh-Enhanced Forced Convection Heat Transfer for the Cooling of High Power Density Mirrors," pp. 43-56, Mirrors and Windows for High Power/High Energy Laser Systems, Klein, C. A., Ed., SPIE Proceedings, Vol. 1047, January 1989.

24. Vandersande, J., et al,. "Thermoelectric Devices and Diamond Films for Temperature Control of High Density Electronic Circuits," 1st Annual Spacecraft Thermal Control Symposium, USAF Phillips Laboratory, November 1994.

25. Eden, R., "Application of Bulk Synthetic Diamond for High Heat Flux Themal Management," SPIE Vol. 1997, High Heat Flux Engineering II, 1993.

26. Robinson, C. J., et al., "Diamond for High Heat Flux Applications," SPIE Vol. 1739, High Heat Flux Engineering, 1992.

27. Duncan, A. B., "An Evaluation of Contemporary Micro Heat Pipe Technology," 9th International Heat Pipe Conference, Albuquerque, NM, May 1995.

28. Klien, C. A., "High Power CW Laser Windows: Edge Cooled or Face-Cooled?," SPIE Vol. 1739, High Heat Flux Engineering, 1992. 
29. Tuckerman, D. B., and Pease, R. F. W., "High Performance Heat Sinking for VLSI," IEEE Electron Device Letters, EDL-2, p. 126, 1981.

30. Tuckerman, D. B., "Heat Transfer Microstructures for Integrated Circuits," Ph.D. Dissertation, Stanford University, Stanford, CA, 1984.

31. Phillips, R. J., "Forced-Convection, Liquid-Cooled Microchannel Heat Sinks," M.S. Thesis, MIT, Cambridge, MA, 1988.

32. Goodling, J. S., "Microchannel Heat Exchangers-A Review," SPIE Vol. 1997, Paper No. 1997-06, High Heat Flux Engineering II, 1993.

33. Hanneman, R. J., "The Computer System of the Eighties: The Impact of Physical Design," Advances in Computer Technology, ASME, Vol. 1, p. 348, 1980.

34. Rahman, M. M., and Gui, F., "Experimental Measurements of Fluid Flow and Heat Transfer in Microchannel Cooling Passages in a Chip Substrate," ASME International Electronic Packaging Conference, Binghampton, NY, 1993.

35. Reinarts, T., et al., "Steady-State and Transient Performance of Cooling Techniques for Microchannel Electronic Chips," 1st Annual Spacecraft Thermal Control Symposium, USAF Phillips Laboratory, November 1994.

36. Sherman, M., and Campbell, G., "State-of-the-Art of Microchannel Cooler Designs and Design Optimization Techniques," 1st Annual Spacecraft Thermal Control Symposium, USAF Phillips Laboratory, November 1994.

37. Carslaw, H. S., and Jaeger, J. C., Conduction of Heat in Solids, 2nd ed., Oxford University Press, Oxford, England, 1978.

38. Riddle, R. A., "Thermal Stresses in the Microchannel Heatsink Cooled by Liquid Nitrogen," SPIE Vol. 1997, High Heat Flux Engineering II, 1993. 


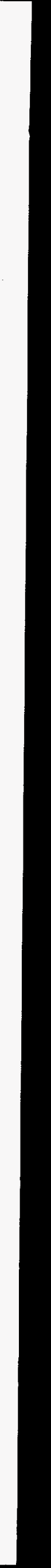




\section{APPENDIX A \\ WINDOW ANALYSIS}

\section{Summary of March 8, 1995, "Thermal Analysis of TPX Windows," by R. Ellis III, G. Gettelfinger, and S. Medley}

1. One-dimensional, free convection on atmosphere side of window, other side adiabatic, uniform internal-heat generation. Arbitrary one-fifth of calculated convection coefficient used. Incident flux $40 \mathrm{~W} / \mathrm{cm}^{2}$. Assumed $0.5 \%$ absorption in 2-cm window. $\Delta \mathrm{T}$ predicted to be $1000^{\circ} \mathrm{C}$.

2. Calculated radiation equilibrium temperature for window surface with $\mathrm{a}=\mathrm{e}$ and $40 \mathrm{~W} / \mathrm{cm}^{2}$ flux. Predicted window temperature of $1359^{\circ} \mathrm{C}$.

3. Discussed change to absorption at inner surface to account for incident energy in UV and shorter wavelengths but used uniform absorption model with radial conduction to $160^{\circ} \mathrm{C}$ outer edge. Used two-dimensional axisymmetric model but axial variation insignificant. Incident flux of $40 \mathrm{~W} / \mathrm{cm}^{2}$. Assumed $0.5 \%$ absorption in 2-cm window. Maximum window temperature of $275^{\circ} \mathrm{C}$ at centerline for $10-\mathrm{cm}$-diam window. No stress calculation. 



\section{APPENDIX B WINDOW SCENARIOS

\author{
TPX Visible/IR/(Near UV?) Viewing Issues \\ (memo from Phil Edmonds, University of Texas-Austin)
}

The purpose of this note is to summarize my understanding of the TPX Diagnostic Organization's position on the subject of windows, mirrors, fiber optics, and plasma viewing.

This is a very informal note and I would appreciate any comments the reader might have.

Three candidates or presently being considered for steering/viewing optically:

- Windows,

- Mirrors,

- Fiber optics.

The various issues will be discussed in the following sections.

\section{HEATING}

The immediate conclusion is that for any significant fraction of the wall power absorbed on the front surface of the window, the front surface will overheat. Some simple cases can be directly calculated using a 1-D calculation. More sophisticated calculations by $\mathrm{R}$. Ellis detail this result.

For this simplistic calculation we will take the easy case in which all the power is absorbed at the front surface and the back plane is cooled. We take a quartz window and select a thermal conductivity of $1.6 \times 10^{-2} \mathrm{Watt} /{ }^{\circ} \mathrm{C}$-cm, appropriate for about $250^{\circ} \mathrm{C}$.

Now the GRD (General Requirement Document) proposes 22.5 MW (half of $45 \mathrm{MW}$ ) radiated in core. Placing the window $20 \mathrm{~cm}$ behind the plasma, at a radius of $0.70 \mathrm{~m}$, with the torus major radius at $2.25 \mathrm{~m}$, and assuming the plasma radiation is isotropic, the energy flux is $36 \mathrm{~W} / \mathrm{cm}^{2}$.

With this input power flux the temperature rise is $225^{\circ} \mathrm{C}$ per millimeter. Now for a quartz window the Oak Ridge National Laboratory report, ORNL/TM-6864, suggests a thickness-to-diameter ratio of about 0.08 . A reasonable limit for the window temperature is, say, $400^{\circ} \mathrm{C}$, so the power loading is about a factor of five too high.

This assumes perfect cooling, for a convection h-parameter of, say, $0.01 \mathrm{~W} /{ }^{\circ} \mathrm{C}-\mathrm{cm}^{-2}$; then the surface temperature differential is $360^{\circ} \mathrm{C}$ for starters. (Note that a water-cooled surface has an $\mathrm{h}$-parameter of order $1 \mathrm{~W} /{ }^{\circ} \mathrm{C}-\mathrm{cm}^{-2}$.) One can imagine a double window with a reduced structural safety factor with coolant flowing in the space between the windows. How this will affect theoptical quality is an interesting question. Transmission bandwidth could also be a problem; however, the coolant doesn't have to be water. At best this cools the back plane to room-like temperatures.

DIII-D allegedly has some problems with surface heating of windows; I am looking into this (David Nilson). People at Tore Supra are aware of the problem but are presently struggling with ten-second problems and will worry about this one when they get to it (Michel Chatelier). 


\section{Conclusion}

If all the power is absorbed on the front surface, the maximum window diameter is about $2 \mathrm{~cm}$, assuming a temperature above $400^{\circ} \mathrm{C}$ is not acceptable. For the real case the back plane will be imperfectly cooled, and this will only make things worse. The proposed window cleaning techniques will almost certainly interfere with cooling concepts.

The power is undoubtedly deposited more uniformly in the window material, and some will penetrate and not be absorbed. These more realistic scenarios have been modeled by R. Ellis. The benefit depends on the power spectrum and the transmission properties of the window. Window coating may drastically modify gains. Clearly the T.S. front lens or window is the most intransigent problem. The aperture is tens of centimeters, and close proximity to the plasma is required. Note that most (if not all) cadioptric systems have a front transmission element for correction.

\section{Possible Remediations}

- Reduced plasma view-apertures and distance from the plasma. First-surface metal mirrors can easily selectively reflect the required frequency range but absorb the wavelengths (UV) which carry the bulk of the energy.

- Shutters to reduce exposure time.

- A rotating disk with most of the area radiating to a cold surface (J. Bialek). The idea is to have a quartz disk rotating fast enough to spread the heat uniformly over the surface. A fraction of the surface will be exposed to the energy flux, and the remainder will be behind a cooled shield. The calculation that follows assumes both surfaces radiate to room temperature and an aperture equal to the disk radius is exposed to the plasma flux. Three results are given, for an emissivity (h) of $1,0.5$, and 0.1 . Input power is $36 \mathrm{~W} / \mathrm{cm}^{2}$. For $\mathrm{h}=1, \mathrm{~T}($ quartz $)=670^{\circ} \mathrm{C}$; for $\mathrm{h}=0.5, \mathrm{~T}($ quartz $)=$ $850^{\circ} \mathrm{C}$; for $\mathrm{h}=0.1, \mathrm{~T}$ (quartz) $=1400^{\circ} \mathrm{C}$. Whether it is possible to find room, clean surfaces, install motors, etc., is another issue.

A simpler version of this concept is simply to use a quartz window in radiative equilibrium as a thermal shield. For the fiducial input power of $36 \mathrm{~W} / \mathrm{cm}^{2}$ and with an emissivity of unity, the surface temperature is a little over $1000^{\circ} \mathrm{C}$. I'm not sure of the consequences of looking through a window at this temperature. (This idea is the present survivor.)

- Magic, such as a plastic film or equivalent moved past the window, from one roller to another. Rollers may be outside the vacuum with a differentially pumped seal, etc.

\section{Action Items}

- Find out what the thickness regs are (Gettelfinger). ORNL TM 6864/Robinson 1980; thickness/diameter $=0.08$ for quartz

- Find out what the thermal conductivities are (Renda). $1.6 \times 10^{-2} \mathrm{Watt}^{\circ} \mathrm{C}-\mathrm{cm}^{2}$, appropriate for quartz at about $250^{\circ} \mathrm{C}$.

- Find values for the power spectrum and absorption length for candidate materials (Ramsey?). 


\section{NUCLEAR DARKENING OR 'BROWNING"}

When exposed to radiation, most transparent glasses and plastics experience transmission loss. There is both an immediate transient acute response during radiation and a long-term chronic loss. The opacity can be removed by annealing at elevated temperatures (order $200^{\circ} \mathrm{C}$ to $400^{\circ} \mathrm{C}$ ) for minutes to hours and, to some extent, by exposure to intense UV or visible light. As I understand it, the explanation is that the radiation produces lattice defects or holes, and these are filled with loosely bound electrons or color centers which can absorb light. Normally, the coloration is brown, but in a few cases the coloration is quite beautiful, a deep blue in certain sapphires, for example. The browning rate is very dependent on material specifics, such as trace elements; synthetic sapphires tend to have low levels of dopants, and these make the material much more prone than natural sapphires. The transmission loss is most rapid in the UV and blue and less so in the red. A study is in progress by G. Miley and others at the University of Illinois (UI) and a private company using the UI reactor. Preliminary results indicate that the damage is accumulative, although after each exposure the annealing returns the glass to almost full transparency. After successive similar exposures the transmission loss is greater.

An evaluation of the importance of this effect, both to window materials and to fiber optics, requires an estimate of the radiation fluxes expected at the window and fiber locations and of the available materials. Some glasses have been developed at ORNL with high resistance to radiation and also high NA values (about 0.6 ). These have been drawn and tested as fibers, but used plastic coatings, and therefore have low temperature limits (Steve Allison). Chris Klepper is monitoring this program. At best, these glasses probably suffer performance loss above $400^{\circ} \mathrm{C}$.

The requirement to maintain windows at elevated temperatures needs to be included in the design of the supporting structures due to differential expansion, etc. (At least the window heating problem nicely balances the elevated temperature requirement.) Parenthetically, the designers will also need to consider electromagnetic loads on the heaters and supporting structure.

Transmission loss may well be controlled simply by maintaining the window/fiber at an elevated temperature. Alan Ramsey [Princeton Plasma Physics Laboratory] is studying the fiber-optic problem (The TPX Optical Fiber Study, a Prolegomenon).

\section{SURFACE COATING}

The front surface of the windows, or other viewing systems, will become coated with redistributed wall materials. In the best of circumstances, these are carbons and hydrocarbons. (Is there life inside a tokamak?) A study of techniques for cleaning this material by laser ablation is in progress. Unanswered questions include the following: What is the coating rate? Is cleaning necessary during the 1000 -second shot? Can we use the laser ablation technique to clean the optics at the far end of the fibers? Many diagnostics will use imaging optics at the fiber head-how to clean these? Chances are, other people (Ramsey?) have a lot of these answers from TFTR. 


\section{SURFACE EROSION}

After some extended exposure I would expect the window/mirror/fiber optic surface to become matte or frosted. I predict an erosion rate of about 50 angstroms per 1000second shot. This implies that in a 100 shots or so, several wavelengths will have been rearranged. The consequences are not clear; it may act as a surface polishing process and take a long time for the surface to degrade. It may turn matte after a few 100 shots. The initial effect is probably to scatter stray light into the viewing solid angle; this is most serious for diagnostics with background light problems, as T.S. or visible Bremsstrahlung. Data from TEXT [Texas Experimental Torus] suggest that mirrors do not suffer surface damage; however, the edge plasma may not be hot enough for significant erosion to occur. There should be some information from TFTR [Tokamak Fusion Test Reactor] and JET [joint European torus], as that plasma is essentially similar to the expected TPX plasmas. (We may launch an experimental study possibly using the SNLA [Sandia National Laboratories, Albuquerque] program. I believe Sandia has a 40-kV (approximately) neutral beam available for this kind of study. (Maybe it has already been done; I would appreciate names to contact.)

\section{RADIATION-INDUCED LOSS OF STRENGTH}

At some radiation level, glasses and other window materials will presumably lose strength; this implies thicker materials, and that impacts all the other issues. Are the radiation levels expected from TPX sufficiently high for this to be a problem? 